\title{
Ferramenta para análise de transparência de dados públicos de municípios do estado de Santa Catarina
}

\section{Title: Tool for transparency analysis of public data of the municipalities of the state of Santa Catarina}

\author{
Artigo submetido à Edição Especial sobre Transparência em Sistemas de \\ Informação
}

\section{Bianca Noceti ${ }^{1}$}

${ }^{1}$ Departamento de Informática e Estatística - Universidade Federal de Santa Catarina (UFSC)

Campus Universitário - Florianópolis - SC - Brasil

bianca.noceti@grad.ufsc.br

\begin{abstract}
Access to information is recognized as a fundamental human right by important organizations in the international community. Given this, Brazil enacted Law no. 12.527/11. The aim of this work is to propose a tool for the analysis of public data transparency that evaluates the quality of transparency of the municipalities of Santa Catarina. The methodology consists of a comparative analysis among the main methods of evaluation, followed by an exploratory study of the portals of the municipalities using the proposed tool. As a result, a tool was obtained in spreadsheet format easy to use even by non-specialists and an average score of 5,5 - on a scale of 0 to 10 - among the studied municipalities.
\end{abstract}

Keywords. Information Access Law; Access to public information; Transparency of public data; Open data.

Resumo. $O$ acesso à informação é reconhecido como direito humano fundamental por importantes organizações da comunidade internacional. Diante disso, o Brasil promulgou a Lei número 12.527/11. O objetivo deste artigo é propor uma ferramenta para análise de transparência de dados públicos que avalie a qualidade de transparência dos municípios catarinenses. A metodologia consiste em uma análise comparativa entre os principais métodos de avaliação, seguido de um estudo exploratório dos portais dos municípios utilizando a ferramenta proposta. Como resultado, obteve-se uma ferramenta em formato de planilha eletrônica de fácil utilização mesmo por não-especialistas e uma nota média de 5,5 - em uma escala de 0 a 10 - entre os municípios estudados.

Palavras-Chave. Lei de acesso à informação; Acesso à informação pública; Transparência de dados públicos; Dados abertos.

\section{Introdução}

Todo ser humano tem direito à liberdade de opinião e de expressão; esse direito inclui a liberdade de ter opiniões sem sofrer interferência e de procurar, receber e divulgar informações e ideias por quaisquer meios, sem limite de fronteiras (ONU, Declaração Universal dos Direitos Humanos, 1948). Além disso, o acesso à informação é um direito

Cite as: $\quad$ Noceti, B. (2019) Tool for transparency analysis of public data of the municipalities of the state of Santa Catarina (Ferramenta para análise de transparência de dados públicos de municípios do estado de Santa Catarina). iSys: Revista Brasileira de Sistemas de Informação (Brazilian Journal of Information Systems), 12(2), 89-116. 
que pertence à coletividade, visto que o acesso amplo a informações públicas resulta em ganhos para a comunidade de maneira geral (CANELA; NASCIMENTO, 2009).

A lei número 12.527 de novembro de 2011 é conhecida como a Lei de Acesso à Informação (LAI) e regulamentou o acesso à informação, previsto na Constituição Federal, assegurando ao cidadão este direito fundamental. Estudos e comentários sobre esta legislação auxiliam na compreensão da importância e do impacto destas normas para a consolidação da democracia (MENDEL, 2009; LINHARES, 2011) e o desenvolvimento de uma cultura de transparência na administração pública (CONTROLADORIA GERAL DA UNIÃO, 2011; CANHADAS, 2012).

Segundo De Ferranti et al. (2009) a transparência em termos de governo referese à disponibilidade pública e oportuna, com qualidade, abrangente e relevante, de informações confiáveis sobre as atividades do governo, sendo essencial para fornecer uma base contínua para a aprovação do governante pelo cidadão. Strong, Lee e Wang (1997) afirmam que as características da qualidade da informação vão para além da correção, ao considerarem aspectos como a apresentação, o acesso e a relevância como componentes importantes. Um conjunto de dados pode estar correto, mas a sua apresentação pode dificultar a sua compreensão ou sua disponibilização pode não ocorrer em tempo útil, diminuindo o aspecto de qualidade da informação ao consumidor (OLIVEIRA; AMARAL, 1999).

Para da Silva et al. (2014), além do provimento da transparência, a política de abertura de dados governamentais possui diversos outros potenciais como a melhoria da gestão pública, o fomento ao controle social, a promoção da participação social e o estímulo à inovação. Sabendo que "a baixa qualidade dos Dados Abertos Governamentais (DAGs) que são disponibilizados é vista como uma das principais barreiras para o processo de desenvolvimento de projetos que utilizam esses dados" (ARAÚJO, 2017), é de suma importância que, além de serem disponibilizados, os dados públicos possuam qualidade e formato adequados para sua real utilização em sistemas informatizados.

Este trabalho tem como primeiro objetivo a realização de uma análise comparativa entre os principais métodos de avaliação de transparência de dados aplicados no Brasil e em outros países. Nesta análise são apontados os principais pontos fortes e fracos de cada métrica verificada, cujos principais aspectos levados em consideração na análise foram a verificação quanto ao formato de disponibilização dos dados, relevante para sua efetiva utilização em sistemas informacionais; a complexidade de implementação, importante para municípios de pequeno porte; a verificação do cumprimento de leis específicas de cada local e se o resultado é de alguma forma influenciado pela subjetividade dos pesquisadores. Para isso, foi realizada a revisão da literatura com os principais conceitos e definições relacionados à Lei de Acesso à Informação $\mathrm{n}^{\circ} 12.527 / 11$ e correlatos, além do levantamento das principais métricas para avaliação de transparência de dados.

O segundo objetivo deste trabalho trata de uma proposta de uma ferramenta prática para avaliação da qualidade da transparência dos dados públicos dos municípios catarinenses, constituído de uma sistematização das principais métricas avaliadas na análise comparativa anterior. Vale destacar que a ferramenta pode ser aplicada em qualquer estado e município, por qualquer cidadão - foi escolhido Santa Catarina por ser o estado de origem. Por fim, a ferramenta é aplicada em municípios de pequeno, médio e grande porte para avaliação da qualidade da transparência de seus dados. 


\section{Fundamentação Teórica}

\subsection{Lei de Acesso à Informação $\mathbf{n}^{0} \mathbf{1 2 . 5 2 7 / 1 1}$}

A Lei de Acesso à Informação (LAI) número 12.527 de 18 de Novembro de 2011, foi implementada na Administração Pública Federal no ano de 2012, a partir do Decreto ${ }^{\circ}$ 7.724 de 16 de maio de 2012 (BRASIL, Ministério da Transparência, Fiscalização e Controladoria-Geral da União, 2016). Esta legislação vale para a administração direta e indireta de todos os Poderes e entes federativos. Sancionada em 18 de novembro de 2011, a Lei $\mathrm{n}^{\circ} 12.527$ teve origem em debates no âmbito do Conselho de Transparência Pública e Combate à Corrupção, órgão vinculado à Controladoria-Geral da União (CGU). A Lei foi discutida e votada pelo Congresso Nacional entre 2009 e 2011 (BRASIL, Controladoria-Geral da União, 2011).

Como consta no Art. 5o da Lei $\mathrm{n}^{\circ}$ 12.527, "é dever do Estado garantir o direito de acesso à informação, que será franqueada, mediante procedimentos objetivos e ágeis, de forma transparente, clara e em linguagem de fácil compreensão" (BRASIL, 2011). O Art. 3o da Lei $\mathrm{n}^{\circ} 12.527$ determina, entre outras diretrizes, que a publicidade é o preceito geral e o sigilo é a exceção, informações de interesse público devem ser divulgadas independentemente de solicitações e devem ser utilizados meios de comunicação viabilizados pela tecnologia da informação. Ainda, à respeito da disponibilização dos dados nos sites, é estabelecido no $\S 30$ do artigo $8^{\circ}$ da LAI, entre outros itens, a possibilidade de gravação de relatórios em diversos formatos eletrônicos, inclusive abertos e não proprietários, tais como planilhas e texto, de modo a facilitar a análise das informações; a possibilidade de acesso automatizado por sistemas externos em formatos abertos, estruturados e legíveis por máquina; manter as informações atualizadas e divulgar em detalhes os formatos utilizados para estruturação da informação.

\subsection{Governo aberto}

De acordo com a Parceria para Governo Aberto (OGP - sigla em inglês de Open Government Partnership), para o governo ser considerado aberto, ele deve buscar alcançar quatro objetivos (BRASIL, 2014):

- Aumentar a disponibilidade de informações sobre atividades governamentais;

- Apoiar a participação social;

- Implementar os padrões mais altos de integridade profissional na Administração;

- Aumentar o acesso a novas tecnologias que promovam a transparência e prestação de contas.

Ainda, a OGP estabelece quatro princípios-chave a serem levados em consideração para a construção de um Governo Aberto:

a) Prestação de contas e responsabilização (accountability): Regras e mecanismos que estabelecem como os atores justificam suas ações, atuam sobre críticas e exigências, e aceitam as responsabilidades que lhes são incumbidas;

b) Transparência: Informações sobre as atividades de governo são abertas, compreensíveis, tempestivas, livremente acessíveis e atendem ao padrão básico de dados abertos;

c) Participação cidadã: O governo deve escutar os cidadãos e empresas e levar em consideração os seus anseios tanto no desenho quanto na implementação das políticas públicas. 
d) Tecnologia e Inovação: O governo reconhece a importância das novas tecnologias no fomento à inovação, provendo acesso à tecnologia e ampliando a capacidade da sociedade de utilizá-la (BRASIL, 2014).

Atualmente, para promover a transparência de seus dados, o Brasil dispõe da Infraestrutura Nacional de Dados Abertos (INDA) como política de promover o acesso aos dados públicos do Poder Executivo Federal para a sociedade e outras instâncias do setor público através do Portal Brasileiro de Dados Abertos (http://dados.gov.br/) (ARAÚJO, 2017).

Além desse portal de nível federal, há outros portais online que disponibilizam dados abertos a níveis estadual e municipal. A partir disso, várias organizações interessadas em DAGs e outros grupos voluntários ajudam a construir conjuntos de dados e diretrizes. Tais organizações promovem discussões e concursos que, aliadas à facilidade de interação através de mídias sociais, atrai cada vez mais interessados a colaborarem uns com os outros no desenvolvimento de projetos que promovem a transparência e a participação cidadã (MATHEUS; RIBEIRO; VAZ, 2011).

\subsection{Dados Abertos}

Segundo a Open Knowledge Foundation (2017), dados abertos são "dados que podem ser livremente usados, reutilizados e redistribuídos por qualquer pessoa - sujeitos, no máximo, à exigência de atribuição da fonte e compartilhamento pelas mesmas regras". A definição completa de dados abertos com detalhes do significado do termo, segundo Davies (2013) é:

- Disponibilidade de acesso: o dado precisa estar disponível por inteiro e por um custo razoável de reprodução, preferencialmente, sem custo, por meio de download na internet, e também deve estar em um formato conveniente e modificável;

- Reuso e redistribuição: o dado precisa ser fornecido em condições que permitam a sua reutilização e redistribuição, incluindo o cruzamento com outros conjuntos de dados;

- Participação universal: todos podem usar, reutilizar e redistribuir, não havendo discriminação contra áreas de atuação, pessoas ou grupos (DAVIES, 2013).

Weinstein e Goldstein (2012) afirmam que dados abertos são precursores do conceito de governo aberto e podem ser vistos como "parceiros". Eles mencionam que o termo "dados abertos" foi cunhado na década de 1970, quando a NASA e a comunidade de ciência e tecnologia norte-americana criou uma série de padrões técnicos que facilitariam o acesso às informações "não processadas". Ainda, afirmam que a base do conceito de governo aberto foi firmada na pressão cívica pela transparência e controle social, baseados na Lei de Acesso à Informação norte-americana. (WEINSTEIN, GOLDSTEIN, 2012, p. 40).

\subsection{Dados Abertos Governamentais}

Os Dados Abertos Governamentais, originários do Governo Aberto, contribuem para que ocorram controle social, fortalecimento da democracia, cidadania ativa, melhorias na administração pública, inovação, cooperação e transparência (HARRISON et al., 2011). Em 2007, na Califórnia (EUA), um grupo de trabalho designado para tratar da disponibilização das informações estatais propôs oito princípios sobre dados abertos governamentais, hoje amplamente aceitos pela comunidade mundial. Assim, dados governamentais são considerados abertos quando publicados de acordo com tais princípios a seguir definidos (DAVIES, 2013; UBALDI, 2013; OPEN GOVERNMENT DATA, 2007):

a) Completos: todos os dados públicos devem ser disponibilizados. Dado público é aquele que não está sujeito a restrições de privacidade, segurança ou outros privilégios. 
b) Primários: são apresentados tal como colhidos da fonte, com o maior nível possível de granularidade, sem agregação ou modificação. Por exemplo, um gráfico não é fornecido aberto, mas os dados utilizados para construir a planilha que deu origem a ele podem ser abertos.

c) Atuais: devem ser publicados o mais rápido possível para preservar seu valor. Em geral, têm periodicidade: quanto mais recentes e atuais, mais úteis para seus usuários.

d) Acessíveis: são disponibilizados para a maior quantidade possível de pessoas, atendendo, assim, aos mais diferentes propósitos.

e) Legíveis por máquina: devem estar estruturados de modo razoável, possibilitando que sejam processados automaticamente. Por exemplo, uma tabela em PDF é muito bem compreendida por pessoas, mas para um computador é apenas uma imagem, já uma tabela em formato estruturado, como CSV ou XML, é processada facilmente por softwares e sistemas.

f) Não discriminatórios: devem estar disponíveis para qualquer pessoa, sem necessidade de cadastro ou qualquer outro procedimento que impeça o acesso. g) Não proprietários: Nenhuma entidade ou organização deve ter controle exclusivo sobre os dados disponibilizados.

h) Licenças livres: não devem estar submetidos a copyrights, patentes, marcas registradas ou regulações de segredo industrial.

O uso de Dados Abertos Governamentais possui grande potencial em prover novos serviços, melhorando a vida dos cidadãos e contribuindo para que governo e sociedade trabalhem melhor. Ainda, esses dados podem ser vistos como uma maneira de apoiar e melhorar a interação entre o governo e os cidadãos quando se torna mais transparente, participativo e colaborativo, ou seja, mais democrático (HARRISON et al., 2011).

\subsection{Ciberativismo e Hacktivismo}

O acesso fácil à informação e a troca rápida de conhecimento promovido pela internet permitiu que pessoas com objetivos e ideias semelhantes pudessem se organizar em grupos para promover discussões e articular ações em prol de um objetivo comum. Ainda, pessoas de diversos lugares podem ter contato com realidades até então desconhecidas e com isso se sensibilizarem e apoiar causas, se mobilizarem em favor de alguma organização participando de ações e protestos online e offline (VEGH, 2003, p. 73).

Para Vegh (2003, p. 71), ciberativismo pode ser definido como "um movimento politicamente motivado que ocorre na internet". Para Silveira (2010), ciberativismo pode ser definido como um conjunto de práticas que acontecem nas redes cibernéticas, principalmente na internet, em benefício de causas culturais, políticas, socioambientais e sociotecnológicas. Já Ugarte (2008), vê o ciberativismo como um meio estratégico para criar alianças entre pessoas que, ao utilizar as ferramentas da internet, propiciam uma quantidade suficiente de informação para promover debate, para que este debate "transcenda à blogosfera e saia à rua, ou modifique, de forma perceptível o comportamento de um número amplo de pessoas" (UGARTE, 2008, p. 111).

Para Silveira (2010), hackers são programadores de computador que solucionam problemas de informática utilizando meios não convencionais. Segundo Steven Levy (1984), os hackers são pessoas com conhecimentos técnicos em informática cuja paixão é inventar programas e desenvolver novas formas de processamento de informação e comunicação eletrônica.

Já Alencar et al. (2009) destaca que "o termo hacker não está associado a indivíduos irresponsáveis que visam penetrar em sistemas computacionais de forma 
ilícita - como é normalmente propagado pela mídia de massa tradicional. Esse tipo de indivíduos que violam sistemas de segurança e quebram códigos computacionais são, especificamente, denominados de crackers e, em geral, são repudiados pelos membros das comunidades internacionais de software livre".

Silveira (2010) afirma que de modo geral, no centro da cultura hacker está difundida a ideia de que as informações e conhecimento não devem ser propriedade de ninguém e, mesmo se forem, "a cópia de informações não agride ninguém dada a natureza intangível dos dados" (SILVEIRA, 2010).

De acordo com Castells (2009), "hackers, ativistas digitais e todo o público que vê a internet como uma ferramenta poderosa começou a dar ainda mais atenção aos temas de transparência pública e democracia de acesso aos dados públicos". Para ele, "as redes horizontais de interação, especialmente as mídias sociais, propiciaram novas formas de comunicação, entre essas a autocomunicação de massa" (CASTELLS, 2009).

O hacktivismo e o ciberativismo se alimentam de dados abertos para produzir informação e conhecimento para sociedade. A falta de disponibilização dos dados, dados desatualizados e em formatos inadequados dificultam o trabalho desses grupos. Visto isso, ao promover uma política de abertura de dados com qualidade, o surgimento de inovações que afetam positivamente a sociedade seria facilitada, além de prevenir a obtenção de informações por meios ilegais.

\subsection{Maturidade de dados abertos com Sistema de Cinco Estrelas}

O processo de abertura de dados contém várias abordagens, com diferentes níveis de complexidade. Com isso, surgiu a necessidade de se criar um modelo de maturidade dos dados abertos. A partir desta necessidade de qualificar as publicações de dados abertos, Tim Berners-Lee, o inventor da web, sugeriu um esquema de 5 estrelas para publicação de dados abertos (OPEN KNOWLEDGE BRASIL, 2013).

Segundo a Open Knowledge Brasil (2013), "a proposta de Tim B-Lee é que cada nova estrela alcançada torne os dados progressivamente mais poderosos, mais fáceis pras pessoas utilizarem". Cada estrela simboliza o cumprimento das condições anteriores mais a atual. Será apresentado a seguir o que cada estrela representa, segundo Hausenblas (2012) e Open Knowledge Brasil (2013):

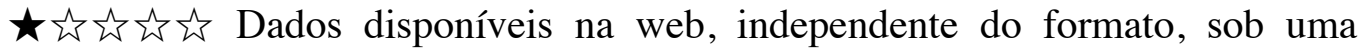
licença aberta (um arquivo no formato PDF sob licença aberta, por exemplo);

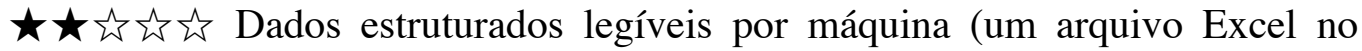
lugar de um PDF com uma tabela, por exemplo);

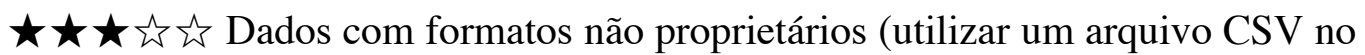
lugar de um Excel, por exemplo);

referenciados;

linkados).

$\star \star \star \star \star$ Dados conectados com outros para prover contexto (dados

De acordo com a Open Knowledge Brasil (2013), as leis brasileiras sobre transparência de dados determinam que para o dado ser considerado aberto, ele deve estar classificado com no mínimo 3 estrelas, ou seja, dados disponíveis na web sob uma licença aberta, estruturados legíveis por máquina e em formatos não proprietários.

\section{Ferramentas de avaliação de transparência de dados}

Esta seção apresenta as principais métricas utilizadas para medir o nível de transparência dos dados e avaliar a qualidade dos mesmos. 


\subsection{Escala Brasil Transparente}

Para medir a transparência pública em estados e municípios brasileiros, o governo brasileiro utiliza a Escala Brasil Transparente (EBT). Esta metodologia avalia o grau de cumprimento de dispositivos da Lei de Acesso à Informação (LAI) e consiste em um checklist composto por 12 quesitos que avaliam aspectos da regulamentação do acesso à informação e a existência e funcionamento do Serviço de Informação ao Cidadão (SIC).

Os seguintes pontos são avaliados (BRASIL, 2017):

I - Regulamentação da Lei de Acesso:

- Exposição da legislação no site do avaliado;

- Existência da regulamentação;

- Regulamentação do SIC;

- Regulamentação da classificação de sigilo;

- Regulamentação da responsabilização do servidor;

- Regulamentação de instâncias recursais.

II - Transparência passiva:

- Divulgação do SIC físico (atendimento presencial);

- Existência de um e-SIC (atendimento pela internet);

- Possibilidade de acompanhamento do pedido de acesso;

- Inexistência de pontos que dificultem ou inviabilizem o pedido de acesso;

- Respostas aos pedidos no prazo legal;

- Respostas em conformidade com o que foi solicitado.

A aplicação do checklist resulta em uma nota de 0 a 10 pontos, onde $25 \%$ da nota é referente à regulamentação da Lei de Acesso à Informação e $75 \%$ à efetiva existência e atuação dos SIC. O preenchimento de cada item do checklist se dá de forma binária, com respostas "SIM" ou "NÃO", com exceção dos casos onde não existe um site ou este estiver fora do ar, contendo os termos "Não Localizado" ou "Site Fora do AR". Escolheu-se o preenchimento binário para que se tenha a menor influência possível da subjetividade do avaliador (BRASIL, 2017). A Figura 1 mostra uma parte do checklist EBT.

\begin{tabular}{|c|c|c|c|c|c|c|c|}
\hline \multicolumn{8}{|c|}{ Checklist EET 3.0} \\
\hline Oedem & \multicolumn{2}{|c|}{ Decalhamento } & Temas/Paralmetros & $\begin{array}{c}\text { PONTUAÇĀO } \\
\text { MAXXMA }\end{array}$ & \begin{tabular}{|c} 
"SiM" OU \\
"NhLO"
\end{tabular} & PONTUAÇĀO & $\boldsymbol{\omega}$ \\
\hline \multicolumn{4}{|c|}{ REGULAMENTAÇĂO } & & & & $25,00 \%$ \\
\hline 1 & \multirow{9}{*}{ Aegulamentaçito } & \multirow{9}{*}{$\begin{array}{c}\text { Verificaklo na } \\
\text { legislastao }\end{array}$} & $\begin{array}{l}\text { O regulamerto foi localizado na poigina } \\
\text { eleschica? } \\
\end{array}$ & 100 & & & 2.76\% \\
\hline \multirow{4}{*}{2} & & & O ente regulamentou a LAI? & 150 & & & $4,17 \%$ \\
\hline & & & \multicolumn{2}{|c|}{$\begin{array}{l}\text { Tipo legal da regulamertachlo (Lei. } \\
\text { Decreto, Portaria, Etc.) }\end{array}$} & & & \\
\hline & & & \multicolumn{2}{|c|}{ Ne do Normativo } & & & \\
\hline & & & \multicolumn{2}{|c|}{ Data do Normativo } & & & \\
\hline 3 & & & Fegulamentou a criaçlo do Sic? & 200 & & & 5,5616 \\
\hline 4 & & & $\begin{array}{c}\text { Existe a previstlo da autoridades que } \\
\text { podem classificar a informactlo quarto } \\
\text { ao grau de sigilo? }\end{array}$ & 150 & & & $4,17 \mathrm{~m}$ \\
\hline 5 & & & $\begin{array}{l}\text { Previsalo de responsabilizaçlo do } \\
\text { servidor em caso de condunas licias; } \\
\end{array}$ & 100 & & & 2,7816 \\
\hline 6 & & & $\begin{array}{l}\text { regulamentod a exisblincia de pelo } \\
\text { menos uma inselncia recursal? }\end{array}$ & 200 & & & 5.5616 \\
\hline
\end{tabular}

Figura 1. Parte do checklist EBT (BRASIL, 2017)

isys: Revista Brasileira de Sistemas de Informação (isys: Brazilian Journal of Information Systems) http://seer.unirio.br/index.php/isys/ 
Todos os itens avaliados têm uma pontuação correspondente atribuída pelos especialistas da Controladoria Geral da União com base no cumprimento ou não do requisito de transparência passiva, que se soma ao cálculo da nota. A pontuação máxima é de 3600 pontos. Como regra, a resposta "SIM" gera pontuação máxima do item e a resposta "NÃO" não gera pontuação, ficando com valor zero (BRASIL, 2017).

Para uma melhor compreensão da sociedade, a nota final é obtida convertendo-se da base 3600 para a base 10 com uma casa decimal de precisão, conforme a equação a seguir:

$$
\text { Nota }=(\text { Pontuação atingida } / 3600) * 10
$$

Segundo o Ministério da Transparência e Controladoria-Geral da União (2017), "a criação de uma nota propiciou um ranking dos entes avaliados em termos de regulamentação e transparência passiva, funcionando o posicionamento dos avaliados como um fator que possibilita e incentiva a melhoria do cenário encontrado".

\subsection{Open Data Barometer}

Produzido pela World Wide Web Foundation como um trabalho colaborativo da rede Open Data for Development (OD4D) e com o suporte da Omidyar Network, o Open Data Barometer (ODB) visa descobrir a verdadeira prevalência e o impacto das iniciativas de dados abertos no mundo. Ele analisa as tendências globais e fornece dados comparativos sobre países e regiões usando uma metodologia detalhada que combina dados contextuais, avaliações técnicas e indicadores secundários (THE OPEN DATA BAROMETER, 2017).

A análise é feita com quatro tipos de levantamento de dados: autoavaliação do governo, respostas de entrevistas com especialistas, avaliações detalhadas de conjuntos de dados e dados secundários.

A autoavaliação do governo consiste num questionário a ser respondido pelo próprio governo, com perguntas como se há uma política ou estratégia de dados abertos bem definida no país, se o país possui leis a respeito de direitos à informação e dados abertos, entre outros.

$\mathrm{Na}$ entrevista com especialistas, é solicitado a especialistas treinados de diversos países para que respondam a uma série de perguntas detalhadas sobre a situação dos dados abertos em um país específico seguindo as indicações do manual de pesquisa. $\mathrm{O}$ manual contém a metodologia detalhada, os principais conceitos, o que deve ser avaliado e quais as pontuações para cada item. ${ }^{1}$

O levantamento de dados secundários utiliza cinco indicadores secundários, cada um selecionado com base na sua capacidade de medir aspectos importantes não cobertos pela pesquisa. Estes indicadores são baseados nas pesquisas de especialistas independentes do World Economic Forum, Freedom House, Departamento de Assuntos Econômicos e Sociais das Nações Unidas e em dados agrupados do Banco Mundial.

As avaliações detalhadas de conjuntos de dados conta com uma equipe de pesquisadores que investiga a disponibilidade de 15 tipos de dados em cada país além de responder a uma lista de verificação de 10 questões em relação à qualidade dos dados fornecidos, gerando uma pontuação entre 0 e 100;

1 É possível acessar o manual completo através do site http://opendatabarometer.org/doc/3rdEdition/ODB-3rdEdition-ResearchHandbook.pdf. 
A lista de verificação da qualidade dos dados é apresentada na Tabela 1.

Tabela 1. Questões do método Open Data Barometer (adaptado de OPEN DATA BAROMETER, 2016; Tradução nossa)

\begin{tabular}{|c|c|c|c|}
\hline Questão & Peso & Lógica encadeada & $\begin{array}{l}\text { Dados qualitativos } \\
\text { coletados }\end{array}$ \\
\hline a - O dado existe? & 5 & $\begin{array}{l}\text { IF } \mathbf{a}=\text { Não THEN } 0 \\
\text { ELSE } 5\end{array}$ & $\begin{array}{l}\text { Descrição dos dados; } \\
\text { Agência responsável; } \\
\text { Razões para a não-coleta; }\end{array}$ \\
\hline $\begin{array}{l}\text { b - Governo disponibilizou online de } \\
\text { alguma forma? }\end{array}$ & 10 & $\begin{array}{l}\text { IF } \mathbf{a}=\text { Não THEN } 0 \\
\text { ELSE } \\
(\text { IF } \mathbf{b}=\text { Sim THEN } 10 \\
\text { ELSE 0) }\end{array}$ & $\begin{array}{l}\text { URL; Limites nos dados } \\
\text { publicados; Políticas que } \\
\text { impedem a publicação; }\end{array}$ \\
\hline $\begin{array}{l}\text { c - O conjunto de dados é fornecido } \\
\text { em formatos legíveis por máquina? }\end{array}$ & 15 & $\begin{array}{l}\text { IF } \mathbf{b}=\text { Não THEN } 0 \\
\text { ELSE } \\
(\text { IF } \mathbf{c}=\text { Sim THEN } 15 \\
\text { ELSE 0) }\end{array}$ & $\begin{array}{l}\text { URL; Formatos de } \\
\text { arquivos; }\end{array}$ \\
\hline $\begin{array}{l}\text { d - Os dados legíveis por máquina } \\
\text { estão disponíveis em massa? }\end{array}$ & 15 & $\begin{array}{l}\text { IF } \mathbf{c}=\text { Não THEN } 0 \\
\text { ELSE } \\
(\text { IF } \mathbf{d}=\text { Sim THEN } 15 \\
\text { ELSE 0) }\end{array}$ & URL; \\
\hline $\begin{array}{l}\text { e - O conjunto de dados está } \\
\text { disponível gratuitamente? }\end{array}$ & 15 & $\begin{array}{l}\text { IF } \mathbf{c}=\text { Não THEN } 0 \\
\text { ELSE } \\
(\text { IF } \mathbf{e}=\text { Sim THEN } 15 \\
\text { ELSE 0) }\end{array}$ & $\begin{array}{l}\text { Detalhes dos regimes de } \\
\text { cobrança }\end{array}$ \\
\hline f - Os dados possuem licença aberta? & 15 & $\begin{array}{l}\text { IF } \mathbf{c}=\text { Não THEN } 0 \\
\text { ELSE } \\
(\text { IF } \mathbf{f}=\text { Sim THEN } 15 \\
\text { ELSE 0) }\end{array}$ & URL; Detalhes da licença; \\
\hline $\begin{array}{l}\text { g - O conjunto de dados está } \\
\text { atualizado? } \\
\text { Lógica: Perde } 5 \text { pontos se os dados } \\
\text { legíveis por máquina estão } \\
\text { desatualizados. Ganha } 10 \text { pontos se } \\
\text { estão atualizados. }\end{array}$ & 10 & $\begin{array}{l}\text { IF } \mathbf{c}=\text { Não THEN } 0 \\
\text { ELSE } \\
(\text { IF } \mathbf{g}=\text { Não THEN -5) } \\
\text { ELSE } \\
(\text { IF } \mathbf{c}=\text { Sim AND } \\
\mathbf{g}=\text { Sim THEN 10) }\end{array}$ & $\begin{array}{l}\text { Data da última } \\
\text { atualização; Frequência de } \\
\text { atualizações; }\end{array}$ \\
\hline $\begin{array}{l}\text { h - A publicação do conjunto de } \\
\text { dados é sustentável? }\end{array}$ & 5 & $\begin{array}{l}\text { IF } \mathbf{c}=\text { Não THEN } 0 \\
\text { ELSE } \\
(\text { IF } \mathbf{h}=\text { Sim THEN } 5 \\
\text { ELSE 0) }\end{array}$ & $\begin{array}{l}\text { Evidência } \\
\text { sustentabilidade; }\end{array}$ \\
\hline $\begin{array}{l}\text { i - Foi fácil encontrar informação } \\
\text { sobre este conjunto de dados? }\end{array}$ & 5 & $\begin{array}{l}\text { IF } \mathbf{c}=\text { Não THEN } 0 \\
\text { ELSE } \\
(\text { IF } \mathbf{i}=\text { Sim THEN } 5 \\
\text { ELSE 0) }\end{array}$ & Notas sobre a descoberta; \\
\hline $\begin{array}{l}\mathbf{j} \text { - As URLs de dados vinculados são } \\
\text { fornecidos para os principais } \\
\text { elementos dos dados? }\end{array}$ & 5 & $\begin{array}{l}\text { IF } \mathbf{c}=\text { Não THEN } 0 \\
\text { ELSE } \\
(\text { IF } \mathbf{j}=\text { Sim THEN } 5 \\
\text { ELSE 0) }\end{array}$ & $\begin{array}{l}\text { URL da publicação dos } \\
\text { dados vinculados; }\end{array}$ \\
\hline
\end{tabular}

Para avaliar o impacto dos dados abertos, os pesquisadores respondem seis questões com uma escala de 0 a 10 . Para isso, eles pesquisam na mídia online, a mídia convencional e publicações acadêmicas sobre os impactos de dados abertos na sociedade. De acordo com Open Data Barometer (2016), as diretrizes de pontuação indicam que as pontuações mais altas devem ser fornecidas apenas para estudos 
revisados, e enfatizam a importância de as fontes estabelecerem uma conexão direta entre os dados abertos e os impactos observados. Para pontuações acima de 5, os pesquisadores são solicitados a citar pelo menos dois exemplos diferentes na categoria dada.

\subsection{Open Data Index}

O Open Data Index (ODI, em inglês), ou Índice de Dados Abertos, é uma ferramenta de ativismo para promover dados abertos, além de ser uma ferramenta de pesquisa para avaliá-los (OPEN DATA CENSUS, 2017c). O Índice de Dados verifica a forma como esses dados são lançados, se estão acessíveis para os cidadãos, mídia e sociedade civil (OPEN DATA CENSUS, 2017). Segundo o Open Data Census (2017), este é o único índice a utilizar pesquisa de colaboração em massa (crowd-sourcing, em inglês) na avaliação da publicação dos dados abertos.

O Open Data Index é formado a partir de uma lista de questões e verificações respondidas por voluntários de cada local de que se deseja avaliar. Então, as respostas são revisadas por especialistas em dados abertos de cada conjunto de dados. A partir daí, em conjunto com a Open Knowledge Network, é produzido um ranking anual de países ou cidades em relação à qualidade da transparência dos dados (OPEN DATA CENSUS, 2017a).

As perguntas respondidas pelos colaboradores em relação à cada dado analisado são informadas a seguir (OPEN DATA CENSUS, 2017c):

- Os dados existem?

- Os dados estão em formato digital?

- Os dados estão disponíveis publicamente?

- Os dados estão disponíveis gratuitamente?

- Os dados estão disponíveis online?

- Os dados são processáveis por máquina?

- Os dados estão disponíveis em massa?

- Os dados são abertamente licenciados?

- Os dados são fornecidos em tempo hábil e atualizados?

Para cada pergunta, há informações sobre como encontrar os dados e quais critérios devem ser levados em conta para as respostas afirmativas.

\section{Análise comparativa}

A métrica Escala Brasil Transparente avalia a regulamentação da lei de acesso à informação nos estados e municípios brasileiros e à efetiva existência e atuação dos SIC (Serviço de Informação ao Cidadão).

Este método de avaliação é concentrado na transparência passiva, avaliando aspectos como: se a solicitação de informação pelo cidadão foi atendida no prazo legal, se a resposta contém todas as informações solicitadas, se é possível acompanhar o pedido de acesso aos dados ou se há pontos que dificultem ou inviabilizem a solicitação. Ainda, é averiguado como é feita a divulgação do SIC físico e se há um e-SIC (atendimento pela internet).

Não há verificação quanto à transparência ativa, ou seja, dos dados e informações que estão disponíveis sem a necessidade de um pedido de acesso. Quanto ao conteúdo da informação, apenas sua completude é avaliada, ou seja, se a informação não está insuficiente, incompleta. Não é verificado o formato como o dado foi 
disponibilizado, por exemplo. Tampouco é analisado se os dados obrigatórios por lei estão sendo disponibilizados, a maneira como são acessados ou a qualidade das informações dispostas.

O método Escala Brasil Transparente é importante para avaliar a transparência passiva, o comportamento dos governos estaduais e municipais quanto à disponibilização de informações solicitadas pelos cidadãos. Entretanto, este método não contempla a transparência ativa e, por não haver um acompanhamento, atualmente os órgãos de controle de transparência não tem conhecimento sobre o cumprimento deste aspecto da lei. Este fato prejudica iniciativas que utilizam dados abertos governamentais para criar aplicações que causem impacto na sociedade.

O método de avaliação Open Data Barometer é focado na transparência ativa dos países, ao contrário do método Escala Brasil Transparente, cujo foco é a transparência passiva.

É um método abrangente: com ele, é possível verificar se o país contém leis sobre acesso e direito à informação, a utilização de dados secundários para complementar as informações, além de averiguar a disponibilidade de 15 tipos de dados e a qualidade em que são apresentados. Ainda, ele oferece uma visão sobre o impacto político, social e econômico que os dados abertos causam na sociedade.

Outro ponto importante é a verificação do formato em que os dados estão disponibilizados de acordo com as principais características da definição de "aberto" segundo a Open Knowledge Internacional: se o dado é legível por máquina, se está disponível em massa, se é gratuito, se possui licença aberta e se está atualizado. Um dado legível por máquina é aquele que tem como objetivo facilitar o acesso automatizado de sistemas informacionais. Um arquivo no formato PDF, por exemplo, não é legível por máquina, pois apesar de suportar muita informação, o computador a interpreta como uma imagem. Já um arquivo em formato de planinha eletrônica, por exemplo, tem seus dados interpretados conforme a informação inserida e podem ser usados de forma direta por computadores.

A avaliação dos conteúdos a serem analisados são separados em temas genéricos, como dados de legislação, dados do desempenho do setor da saúde, entre outros, cabendo ao pesquisador julgar sobre até que ponto o país disponibiliza os dados de determinado tema. Outro ponto que depende do julgamento do pesquisador é a resposta para a questão "foi fácil encontrar informação sobre este conjunto de dados?". Respostas que dependem do julgamento ou entendimento individual tornam o resultado da análise menos preciso, visto que a resposta para a mesma pergunta a respeito da mesma informação pode variar de acordo com o pesquisador.

Por ser um método utilizado para avaliação de diversos países, ele não avalia aspectos específicos de cada país, como cumprimento de determinada lei, se há informações disponibilizadas de forma incorreta ou se algum conteúdo deveria estar acessível mas não está.

Este método oferece informações importantes aos países que desejam melhorar ou implementar uma política de abertura de dados, principalmente sobre os impactos que são gerados na sociedade a partir da iniciativa de abertura dos dados. Contudo, não é recomendável utilizar o Open Data Barometer para avaliar apenas cidades de forma isolada devido à sua complexidade e demanda de esforço e, consequentemente, tempo.

O método de avaliação Open Data Index é interessante para acompanhar a qualidade da transparência de dados em relação às outras cidades de diversos países, visto que a metodologia é padronizada independente do local de aplicação. Ainda, este método é menos complexo se comparado com o Open Data Barometer, visto que demandam menos participação do governo e as verificações dos dados são feitas por voluntários e não pesquisadores especializados, como no Open Data Barometer. 
Entretanto, ainda há a necessidade de especialistas para a revisão dos questionários realizados pelos voluntários. Ainda, por se tratar de um índice internacional, assim como no Open Data Barometer, não há validação a respeito de aspectos específicos de cada país, como cumprimento de determinada lei ou se algum conteúdo específico deveria estar disponibilizado, por exemplo.

Um aspecto do Open Data Index que vale ressaltar é a realização da análise dos dados por voluntários, o que pode estimular as pessoas a participarem mais de assuntos relacionados à transparência de dados governamentais e acompanharem a disponibilização dos mesmos, bem como incentivá-las a usarem de fato os dados para promoverem melhorias à sociedade.

A Tabela 2 apresenta um resumo da análise comparativa feita entre os principais métodos de avaliação de transparência de dados públicos, apontando os principais pontos fortes e fracos de cada método.

Tabela 2. Resumo da análise de métodos (fonte: elaborado pela autora)

\begin{tabular}{|c|c|c|}
\hline Método & Pontos Fortes & Pontos Fracos \\
\hline $\begin{array}{l}\text { Escala Brasil } \\
\text { Transparente }\end{array}$ & $\begin{array}{l}\text { - Específico para o Brasil, avalia } \\
\text { cumprimento da lei; } \\
\text { - Simples, não depende de especialistas; } \\
\text { - Respostas binárias, resultado não } \\
\text { depende de subjetividade do avaliador; }\end{array}$ & $\begin{array}{l}\text { - Não avalia transparência ativa; } \\
\text { - Não avalia o formato dos dados } \\
\text { disponibilizados; }\end{array}$ \\
\hline $\begin{array}{l}\text { Open Data } \\
\text { Barometer }\end{array}$ & $\begin{array}{l}\text { - Padronizado internacionalmente, } \\
\text { permite comparação com outros países; } \\
\text { - Avalia o formato dos dados } \\
\text { disponibilizados; } \\
\text { - Analisa o impacto político, social e } \\
\text { econômico da transparência dos dados } \\
\text { governamentais; }\end{array}$ & $\begin{array}{l}\text { - Não avalia transparência passiva; } \\
\text { - Complexo, depende de pesquisadores } \\
\text { e especialistas; } \\
\text { - Resultado depende do julgamento dos } \\
\text { pesquisadores; } \\
\text { - Não abrange características } \\
\text { específicas das leis locais; } \\
\text { - Apenas para países; }\end{array}$ \\
\hline
\end{tabular}




\begin{tabular}{|c|c|c|}
\hline $\begin{array}{l}\text { Open Data } \\
\text { Index }\end{array}$ & $\begin{array}{l}\text { - Padronizado internacionalmente, } \\
\text { permite comparação com outras cidades } \\
\text { de países diferentes; } \\
\text { - Avalia o formato dos dados } \\
\text { disponibilizados; }\end{array}$ & $\begin{array}{l}\text { - Não avalia transparência passiva; } \\
\text { - Complexo, depende de voluntários e } \\
\text { de especialistas; } \\
\text { - Resultado depende do julgamento dos } \\
\text { voluntários; } \\
\text { - Não abrange características } \\
\text { específicas das leis locais; }\end{array}$ \\
\hline
\end{tabular}

Dentre os métodos analisados, o Escala Brasil Transparente é o que possui menos características em comum com os demais, dificultando sua utilização para comparação internacional em relação à transparência ativa, bem como em relação ao formato dos dados disponibilizados.

Os principais aspectos levados em consideração na análise foram a verificação quanto ao formato de disponibilização dos dados, relevante para sua efetiva utilização em sistemas informacionais; a complexidade de implementação, importante para municípios de pequeno porte; a verificação do cumprimento de leis específicas de cada local e se o resultado é de alguma forma influenciado pela subjetividade dos pesquisadores.

\section{Ferramenta Escala Santa Catarina Transparente}

Até a data do presente trabalho, a ferramenta utilizada pelo governo brasileiro para medir a qualidade da transparência dos dados governamentais é a Escala Brasil Transparente (EBT). Ela é composta por um checklist com opções de resposta binárias, para evitar subjetividade; em formato de planilha eletrônica, portanto legível por máquina, porém com extensão "xls", para software licenciado. Ainda, seu objetivo é avaliar a transparência passiva. A análise feita sobre a EBT levantou dois pontos fracos principais: ela não avalia a transparência ativa, tampouco o formato dos dados disponibilizados. Com base nessas informações, optou-se por desenvolver uma nova ferramenta de avaliação da transparência de dados que inclua os aspectos omitidos no método anterior, de modo que os resultados de ambas ferramentas possam ser usados em conjunto, de forma complementar. Outro ponto levado em consideração foi manter a métrica simples, de maneira que os pequenos municípios possam utilizá-la para autoavaliação sem a necessidade de especialistas.

O nome sugerido para a nova ferramenta é Escala Santa Catarina Transparente, ficando a critério de cada município sua utilização ou redefinição. Ela é composta por um checklist com opção de resposta binária, em formato de planilha eletrônica com extensão ".ods" (OpenDocument - padrão ISO/IEC 26300). Portanto, evitará ao máximo a subjetividade do avaliador, é legível por máquina e livre de softwares licenciados. O objeto de avaliação é o site oficial de cada município e a análise é concentrada na transparência ativa e no formato em que os dados estão disponibilizados.

As características de dados abertos governamentais são resumidas em três "leis" sugeridas pelo ativista dos dados abertos David Eaves (2009):

1. Se o dado não pode ser encontrado ou indexado na web, ele não existe;

2. Se o dado não está disponível num formato aberto e legível por máquina, ele não pode ser r reutilizado; 3. Se dispositivos legais não permitem que ele seja compartilhado e reutilizado, ele não é útil (EAVES, 2009; tradução nossa).

Ainda, a respeito da disponibilização dos dados nos sites de acordo com o $§ 30$ do artigo $8^{\circ}$ da Lei de Acesso à Informação, vale destacar os seguintes itens:

II - possibilitar a gravação de relatórios em diversos formatos eletrônicos, inclusive abertos e não proprietários, tais como planilhas e texto, de modo a facilitar a análise das informações; 
III - possibilitar o acesso automatizado por sistemas externos em formatos abertos, estruturados e legíveis por máquina;

Visto isso, a métrica utilizada é baseada no sistema cinco estrelas abordado anteriormente, e os critérios avaliados no checklist são a respeito da disponibilidade online do dado, se ele está atualizado e de que forma ele está disponível.

O formato das questões criadas, bem como o método de pontuação com resposta binária foi inspirado nas ferramentas analisadas Open Data Barometer e Escala Brasil Transparente, porém a lógica encadeada utilizada no Open Data Barometer entre as questões foi retirada, mantendo a pontuação de cada questão independente entre si. O cálculo da nota final seguiu o padrão realizado na ferramenta Escala Brasil Transparente.

O cabeçalho da planilha é composto pelo nome da ferramenta, sua versão (neste caso é 1.0), o nome do município avaliado, seu site e a data de avaliação. Em seguida, as colunas são divididas em: Item avaliado; Número da questão; Questões; Pontos da questão; Resposta; Pontuação. As questões têm como resposta as opções de "1", equivalente à "Sim" ou "0", equivalente à "Não". Apenas as questões respondidas com "1" são pontuadas. As questões definidas com suas respectivas justificativas e pontuações são apresentadas na Tabela 3 .

Tabela 3. Critérios avaliados Escala SC Transparente (fonte: elaborado pela autora)

\begin{tabular}{|c|c|c|c|}
\hline $\mathbf{N}^{\mathbf{0}}$ & Questões & Pontos & Justificativa \\
\hline 1 & $\begin{array}{l}\text { O site possui } \operatorname{link}(\mathrm{s}) \text { para acessar } \\
\text { o dado? }\end{array}$ & 10 & $\begin{array}{l}\text { Verificar se o dado está disponível online; Separado } \\
\text { entre existência de link e dado pois foi verificado } \\
\text { que em alguns sites há apenas o link, sem nenhum } \\
\text { dado. }\end{array}$ \\
\hline 2 & $\begin{array}{l}\text { O link contém o determinado } \\
\text { dado? }\end{array}$ & 240 & $\begin{array}{l}\text { Verificar se o dado está disponível online no site } \\
\text { oficial do município, conforme exigido em lei e nos } \\
\text { princípios de abertura de dados governamentais. }\end{array}$ \\
\hline 3 & O dado está atualizado? & 250 & $\begin{array}{l}\text { Dados precisam estar atualizados para ter utilidade, } \\
\text { além de ser exigido por lei (Item VI do } \S 30 \text { do } \\
\text { artigo } 8^{\circ} \text { da LAI). }\end{array}$ \\
\hline 4 & O dado está sob licença aberta? & 250 & $\begin{array}{l}\text { Baseado no critério de } 1 \text { estrela: dados disponíveis } \\
\text { na } w e b \text {, independente do formato, sob uma licença } \\
\text { aberta. }\end{array}$ \\
\hline 5 & $\begin{array}{l}\text { É um dado estruturado legível } \\
\text { por máquina? (um arquivo } \\
\text { Excel no lugar de um PDF com } \\
\text { uma tabela, por exemplo) }\end{array}$ & 600 & $\begin{array}{l}\text { Baseado no critério de } 2 \text { estrelas: dados estruturados } \\
\text { legíveis por máquina. }\end{array}$ \\
\hline 6 & $\begin{array}{l}\text { O dado possui formato não } \\
\text { proprietário? (Não é necessário } \\
\text { um sistema com licença paga, } \\
\text { como doc ou xls para acessá- } \\
\text { lo) }\end{array}$ & 250 & $\begin{array}{l}\text { Baseado no critério de } 3 \text { estrelas: dados com } \\
\text { formatos não proprietários. }\end{array}$ \\
\hline 7 & $\begin{array}{l}\text { O dado utiliza URIs para } \\
\text { identificação, para que possa ser } \\
\text { referenciado? }\end{array}$ & 200 & $\begin{array}{l}\text { Baseado no critério de } 4 \text { estrelas: são utilizados } \\
\text { URIs para identificar os dados, para que possam ser } \\
\text { referenciados; }\end{array}$ \\
\hline 8 & O dado está conectado com & 200 & Baseado no critério de 5 estrelas: dados conectados \\
\hline
\end{tabular}


outros para prover contexto? (dados linkados) com outros para prover contexto.

A pontuação máxima que se pode obter é 2000 pontos. A partir do que se espera de um portal de transparência municipal, optou-se por escolher itens que têm sua disponibilidade exigidas por lei, sendo diário oficial, leis municipais, remuneração dos servidores, despesa geral, receita geral e balanço orçamentário, como também itens que não estão explicitamente indicados como obrigatórios mas que são de responsabilidade dos municípios, como a quantidade de alunos por escola fundamental e os horários por linha do transporte público.

Exclusivamente para o item Diário Oficial, há ainda a seguinte questão: "1.1 Há outro link de outro site para acesso ao dado? (Acesso independente, sem redirecionamento a partir do site oficial analisado)", seguindo o mesmo padrão de resposta binária "Sim" ou "Não", porém sem pontuação mesmo em caso afirmativo. A necessidade de criação desta questão se deu devido ao fato de que a Federação Catarinense de Municípios (FECAM) disponibiliza o Diário Oficial dos Municípios DOM, um canal $^{2}$ de divulgação de atos oficiais administrativos mantida pelo Consórcio de Informática na Gestão Pública Municipal - CIGA, entidade do Sistema FECAM³ .

Optou-se por não pontuar esta questão pois o objetivo é que os dados possam ser acessados a partir de um único site, mesmo que o site possua um link que o redirecione para outro. Neste caso, a questão refere-se à um acesso independente a outro site, sem redirecionamento a partir do site oficial analisado. Ainda, por esta questão não ter pontuação, não é necessário adaptar a fórmula de cálculo da nota especificamente para o item Diário Oficial, mantendo o padrão com os demais itens.

Similarmente à Escala Brasil Transparente, para uma melhor compreensão da sociedade, a nota final dos itens é convertida da base 2000 para a base 10 com uma casa decimal de precisão. A equação completa é ilustrada na Equação 1 a seguir:

\section{Nota total do item avaliado $=($ Total pontuação obtida $/$ Pontuação máxima $) * 10$}

Para a nota final do município, foi utilizado uma média simples das notas de cada item com uma casa decimal de precisão, conforme a Equação 2:

\section{Nota do município $=\sum$ Notas dos itens avaliados $/$ Número de itens avaliados}

A quantidade de pontos para cada questão foi determinada de acordo com a importância das características avaliadas para o efetivo uso dos dados em sistemas informacionais. A ferramenta propriamente dita é mostrada na Tabela 4.

Tabela 4. Ferramenta Escala Santa Catarina Transparente

\begin{tabular}{|c|c|c|c|}
\hline \multicolumn{2}{|r|}{ Escala Santa Catarina Transparente } & Versão: & 10 \\
\hline \multicolumn{4}{|l|}{ Município: } \\
\hline Site oficial: & & Data: & \\
\hline
\end{tabular}




\begin{tabular}{|c|c|c|c|c|c|}
\hline Item avaliado & $\mathbf{N}^{\mathbf{o}}$ & Questões & $\begin{array}{c}\text { Pontos } \\
\text { da } \\
\text { questão }\end{array}$ & Resposta & Pontuação \\
\hline \multirow{12}{*}{ Diário oficial } & 1 & O site possui link(s) para acessar o dado? & 10 & & $\mathbf{0}$ \\
\hline & 1.1 & $\begin{array}{l}\text { Há outro link de outro site para acesso ao dado? } \\
\text { (Acesso independente, sem redirecionamento a } \\
\text { partir do site oficial analisado) }\end{array}$ & 0 & & $\mathbf{0}$ \\
\hline & 2 & O link contém o determinado dado? & 240 & & $\mathbf{0}$ \\
\hline & 3 & O dado está atualizado? & 250 & & $\mathbf{0}$ \\
\hline & 4 & O dado está sob licença aberta? & 250 & & $\mathbf{0}$ \\
\hline & 5 & $\begin{array}{l}\text { É um dado estruturado legível por máquina? (uma } \\
\text { planilha no lugar de um PDF com uma tabela, por } \\
\text { exemplo) }\end{array}$ & 600 & & $\mathbf{0}$ \\
\hline & 6 & $\begin{array}{l}\text { O dado possui formato não proprietário? (Não é } \\
\text { necessário um sistema com licença paga, } \\
\text { como doc ou xls para acessá-lo) }\end{array}$ & 250 & & $\mathbf{0}$ \\
\hline & 7 & $\begin{array}{l}\text { O dado utiliza URIs para identificação, para que } \\
\text { possa ser referenciado? }\end{array}$ & 200 & & $\mathbf{0}$ \\
\hline & 8 & $\begin{array}{l}\text { O dado está conectado com outros para prover } \\
\text { contexto? (dados linkados) }\end{array}$ & 200 & & $\mathbf{0}$ \\
\hline & & Pontuação máxima: & 2000 & Total: & $\mathbf{0}$ \\
\hline & & Opções de resposta: & $\operatorname{Sim}=1$ & Não $=0$ & - \\
\hline & \multicolumn{4}{|c|}{ TOTAL ITEM: } & $\mathbf{0 , 0}$ \\
\hline \multirow{11}{*}{$\begin{array}{l}\text { Leis } \\
\text { Municipais }\end{array}$} & 1 & O site possui link(s) para acessar o dado? & 10 & & $\mathbf{0}$ \\
\hline & 2 & O link contém o determinado dado? & 240 & & $\mathbf{0}$ \\
\hline & 3 & O dado está atualizado? & 250 & & $\mathbf{0}$ \\
\hline & 4 & O dado está sob licença aberta? & 250 & & $\mathbf{0}$ \\
\hline & 5 & $\begin{array}{l}\text { É um dado estruturado legível por máquina? (uma } \\
\text { planilha no lugar de um PDF com uma tabela, por } \\
\text { exemplo) }\end{array}$ & 600 & & $\mathbf{0}$ \\
\hline & 6 & $\begin{array}{l}\text { O dado possui formato não proprietário? (Não é } \\
\text { necessário um sistema com licença paga, } \\
\text { como .doc ou xls para acessá-lo) }\end{array}$ & 250 & & $\mathbf{0}$ \\
\hline & 7 & $\begin{array}{l}\text { O dado utiliza URIs para identificação, para que } \\
\text { possa ser referenciado? }\end{array}$ & 200 & & $\mathbf{0}$ \\
\hline & 8 & $\begin{array}{l}\text { O dado está conectado com outros para prover } \\
\text { contexto? (dados linkados) }\end{array}$ & 200 & & $\mathbf{0}$ \\
\hline & & Pontuação máxima: & 2000 & Total: & $\mathbf{0}$ \\
\hline & & Opções de resposta: & $\operatorname{Sim}=1$ & $\mathbf{N a ̃ o}=\mathbf{0}$ & - \\
\hline & \multicolumn{4}{|c|}{ TOTAL ITEM: } & $\mathbf{0 , 0}$ \\
\hline \multirow{4}{*}{$\begin{array}{c}\text { Educação: } \\
\text { Quantidade } \\
\text { de alunos por } \\
\text { escola } \\
\text { fundamental }\end{array}$} & 1 & O site possui link(s) para acessar o dado? & 10 & & $\mathbf{0}$ \\
\hline & 2 & O link contém o determinado dado? & 240 & & $\mathbf{0}$ \\
\hline & 3 & O dado está atualizado? & 250 & & $\mathbf{0}$ \\
\hline & 4 & O dado está sob licença aberta? & 250 & & $\mathbf{0}$ \\
\hline
\end{tabular}




\begin{tabular}{|c|c|c|c|c|c|}
\hline & 5 & $\begin{array}{l}\text { É um dado estruturado legível por máquina? (uma } \\
\text { planilha no lugar de um PDF com uma tabela, por } \\
\text { exemplo) }\end{array}$ & 600 & & $\mathbf{0}$ \\
\hline & 6 & $\begin{array}{l}\text { O dado possui formato não proprietário? (Não é } \\
\text { necessário um sistema com licença paga, } \\
\text { como doc ou xls para acessá-lo) }\end{array}$ & 250 & & $\mathbf{0}$ \\
\hline & 7 & $\begin{array}{l}\text { O dado utiliza URIs para identificação, para que } \\
\text { possa ser referenciado? }\end{array}$ & 200 & & $\mathbf{0}$ \\
\hline & 8 & $\begin{array}{l}\text { O dado está conectado com outros para prover } \\
\text { contexto? (dados linkados) }\end{array}$ & 200 & & $\mathbf{0}$ \\
\hline & & Pontuação máxima: & 2000 & Total: & $\mathbf{0}$ \\
\hline & & Opções de resposta: & $\operatorname{Sim}=1$ & Não $=0$ & - \\
\hline & \multicolumn{4}{|c|}{ TOTAL ITEM: } & $\mathbf{0 , 0}$ \\
\hline \multirow{11}{*}{$\begin{array}{l}\text { Transporte } \\
\text { Público: } \\
\text { Horários por } \\
\quad \text { linha }\end{array}$} & 1 & O site possui link(s) para acessar o dado? & 10 & & $\mathbf{0}$ \\
\hline & 2 & O link contém o determinado dado? & 240 & & $\mathbf{0}$ \\
\hline & 3 & O dado está atualizado? & 250 & & $\mathbf{0}$ \\
\hline & 4 & O dado está sob licença aberta? & 250 & & $\mathbf{0}$ \\
\hline & 5 & $\begin{array}{l}\text { É um dado estruturado legível por máquina? (uma } \\
\text { planilha no lugar de um PDF com uma tabela, por } \\
\text { exemplo) }\end{array}$ & 600 & & $\mathbf{0}$ \\
\hline & 6 & $\begin{array}{l}\text { O dado possui formato não proprietário? (Não é } \\
\text { necessário um sistema com licença paga, } \\
\text { como .doc ou xls para acessá-lo) }\end{array}$ & 250 & & $\mathbf{0}$ \\
\hline & 7 & $\begin{array}{l}\text { O dado utiliza URIs para identificação, para que } \\
\text { possa ser referenciado? }\end{array}$ & 200 & & $\mathbf{0}$ \\
\hline & 8 & $\begin{array}{l}\text { O dado está conectado com outros para prover } \\
\text { contexto? (dados linkados) }\end{array}$ & 200 & & $\mathbf{0}$ \\
\hline & & Pontuação máxima: & 2000 & Total: & $\mathbf{0}$ \\
\hline & & Opções de resposta: & Sim $=1$ & Não $=0$ & - \\
\hline & \multicolumn{4}{|c|}{ TOTAL ITEM: } & $\mathbf{0 , 0}$ \\
\hline \multirow{10}{*}{$\begin{array}{l}\text { Remuneração } \\
\text { dos servidores }\end{array}$} & 1 & O site possui link(s) para acessar o dado? & 10 & & $\mathbf{0}$ \\
\hline & 2 & O link contém o determinado dado? & 240 & & $\mathbf{0}$ \\
\hline & 3 & O dado está atualizado? & 250 & & $\mathbf{0}$ \\
\hline & 4 & O dado está sob licença aberta? & 250 & & $\mathbf{0}$ \\
\hline & 5 & $\begin{array}{l}\text { É um dado estruturado legível por máquina? (uma } \\
\text { planilha no lugar de um PDF com uma tabela, por } \\
\text { exemplo) }\end{array}$ & 600 & & $\mathbf{0}$ \\
\hline & 6 & $\begin{array}{l}\text { O dado possui formato não proprietário? (Não é } \\
\text { necessário um sistema com licença paga, } \\
\text { como .doc ou xls para acessá-lo) }\end{array}$ & 250 & & $\mathbf{0}$ \\
\hline & 7 & $\begin{array}{l}\text { O dado utiliza URIs para identificação, para que } \\
\text { possa ser referenciado? }\end{array}$ & 200 & & $\mathbf{0}$ \\
\hline & 8 & $\begin{array}{l}\text { O dado está conectado com outros para prover } \\
\text { contexto? (dados linkados) }\end{array}$ & 200 & & $\mathbf{0}$ \\
\hline & & Pontuação máxima: & 2000 & Total: & $\mathbf{0}$ \\
\hline & & Opções de resposta: & $\operatorname{Sim}=1$ & Não $=0$ & - \\
\hline
\end{tabular}




\begin{tabular}{|c|c|c|c|c|c|}
\hline & & & \multicolumn{2}{|c|}{ TOTAL ITEM: } & $\mathbf{0 , 0}$ \\
\hline \multirow{11}{*}{$\begin{array}{l}\text { Despesa } \\
\text { Geral }\end{array}$} & 1 & O site possui link(s) para acessar o dado? & 10 & & $\mathbf{0}$ \\
\hline & 2 & O link contém o determinado dado? & 240 & & $\mathbf{0}$ \\
\hline & 3 & O dado está atualizado? & 250 & & $\mathbf{0}$ \\
\hline & 4 & O dado está sob licença aberta? & 250 & & $\mathbf{0}$ \\
\hline & 5 & $\begin{array}{l}\text { É um dado estruturado legível por máquina? (uma } \\
\text { planilha no lugar de um PDF com uma tabela, por } \\
\text { exemplo) }\end{array}$ & 600 & & $\mathbf{0}$ \\
\hline & 6 & $\begin{array}{l}\text { O dado possui formato não proprietário? (Não é } \\
\text { necessário um sistema com licença paga, } \\
\text { como doc ou xls para acessá-lo) }\end{array}$ & 250 & & $\mathbf{0}$ \\
\hline & 7 & $\begin{array}{l}\text { O dado utiliza URIs para identificação, para que } \\
\text { possa ser referenciado? }\end{array}$ & 200 & & $\mathbf{0}$ \\
\hline & 8 & $\begin{array}{l}\text { O dado está conectado com outros para prover } \\
\text { contexto? (dados linkados) }\end{array}$ & 200 & & $\mathbf{0}$ \\
\hline & & Pontuação máxima: & 2000 & Total: & $\mathbf{0}$ \\
\hline & & Opções de resposta: & Sim $=1$ & Não = 0 & - \\
\hline & \multicolumn{4}{|c|}{ TOTAL ITEM: } & $\mathbf{0 , 0}$ \\
\hline \multirow{11}{*}{ Receita Geral } & 1 & O site possui link(s) para acessar o dado? & 10 & & $\mathbf{0}$ \\
\hline & 2 & O link contém o determinado dado? & 240 & & $\mathbf{0}$ \\
\hline & 3 & O dado está atualizado? & 250 & & $\mathbf{0}$ \\
\hline & 4 & O dado está sob licença aberta? & 250 & & $\mathbf{0}$ \\
\hline & 5 & $\begin{array}{l}\text { É um dado estruturado legível por máquina? (uma } \\
\text { planilha no lugar de um PDF com uma tabela, por } \\
\text { exemplo) }\end{array}$ & 600 & & $\mathbf{0}$ \\
\hline & 6 & $\begin{array}{l}\text { O dado possui formato não proprietário? (Não é } \\
\text { necessário um sistema com licença paga, } \\
\text { como .doc ou xls para acessá-lo) }\end{array}$ & 250 & & $\mathbf{0}$ \\
\hline & 7 & $\begin{array}{l}\text { O dado utiliza URIs para identificação, para que } \\
\text { possa ser referenciado? }\end{array}$ & 200 & & $\mathbf{0}$ \\
\hline & 8 & $\begin{array}{l}\text { O dado está conectado com outros para prover } \\
\text { contexto? (dados linkados) }\end{array}$ & 200 & & $\mathbf{0}$ \\
\hline & & Pontuação máxima: & 2000 & Total: & $\mathbf{0}$ \\
\hline & & Opções de resposta: & Sim $=1$ & Não $=0$ & - \\
\hline & \multicolumn{4}{|c|}{ TOTAL ITEM: } & $\mathbf{0 , 0}$ \\
\hline \multirow{5}{*}{$\begin{array}{c}\text { Balanço } \\
\text { Orçamentário }\end{array}$} & 1 & O site possui link(s) para acessar o dado? & 10 & & $\mathbf{0}$ \\
\hline & 2 & O link contém o determinado dado? & 240 & & $\mathbf{0}$ \\
\hline & 3 & O dado está atualizado? & 250 & & $\mathbf{0}$ \\
\hline & 4 & O dado está sob licença aberta? & 250 & & $\mathbf{0}$ \\
\hline & 5 & $\begin{array}{l}\text { É um dado estruturado legível por máquina? (uma } \\
\text { planilha no lugar de um PDF com uma tabela, por } \\
\text { exemplo) }\end{array}$ & 600 & & $\mathbf{0}$ \\
\hline
\end{tabular}




\begin{tabular}{|c|c|c|c|c|c|}
\hline & 6 & $\begin{array}{l}\text { O dado possui formato não proprietário? (Não é } \\
\text { necessário um sistema com licença paga, } \\
\text { como doc ou xls para acessá-lo) }\end{array}$ & 250 & & $\mathbf{0}$ \\
\hline & 7 & $\begin{array}{l}\text { O dado utiliza URIs para identificação, para que } \\
\text { possa ser referenciado? }\end{array}$ & 200 & & 0 \\
\hline & & $\begin{array}{l}\text { O dado está conectado com outros para prover } \\
\text { contexto? (dados linkados) }\end{array}$ & 200 & & $\mathbf{0}$ \\
\hline & & Pontuação máxima: & 2000 & Total: & $\mathbf{0}$ \\
\hline & & Opções de resposta: & Sim = 1 & Não $=0$ & - \\
\hline & \multicolumn{4}{|c|}{ TOTAL ITEM: } & $\mathbf{0 , 0}$ \\
\hline
\end{tabular}

\begin{tabular}{|c|c|c|}
\hline \multicolumn{3}{|c|}{ Pontuação final do município } \\
\hline \multicolumn{2}{|r|}{ Item avaliado } & \multirow{2}{*}{$\begin{array}{r}\text { Nota } \\
\mathbf{0 , 0}\end{array}$} \\
\hline 1 & Diário Oficial & \\
\hline 2 & Leis Municipais & $\mathbf{0 , 0}$ \\
\hline 3 & Educação: Quantidade de alunos por escola & $\mathbf{0 , 0}$ \\
\hline 4 & Transporte Público: Horários por linha & $\mathbf{0 , 0}$ \\
\hline 5 & Remuneração dos servidores & $\mathbf{0 , 0}$ \\
\hline 6 & Despesa Geral & $\mathbf{0 , 0}$ \\
\hline 7 & Receita Geral & $\mathbf{0 , 0}$ \\
\hline \multirow[t]{2}{*}{8} & Balanço Orçamentário & $\mathbf{0 , 0}$ \\
\hline & TOTAL DO MUNICÍPIO: & $\mathbf{0 , 0}$ \\
\hline
\end{tabular}

\section{Aplicação da ferramenta em sites de municípios catarinenses}

Para a aplicação da ferramenta Escala Santa Catarina Transparente, foi determinada a seleção de 12 municípios catarinenses, divididos entre pequeno, médio e grande porte, com 4 municípios em cada classificação.

Com base na categorização do $\mathrm{IBGE}^{4}$, consideram-se como cidades de pequeno porte aquelas com até 50.000 habitantes, entre 50.001 e 500.000 habitantes como médio, e acima de 500.001 como grande porte. Entretanto, seguindo a definição do IBGE, no estado de Santa Catarina apenas o município de Joinville se enquadra como grande porte, com uma estimativa de população de $577.077^{5}$ pessoas para 2017. Sendo assim, optou-se por usar uma categorização própria para o presente trabalho: serão considerados de pequeno porte municípios de até 50.000 habitantes, de médio porte entre 50.001 e 150.000 habitantes e, por fim, municípios de grande porte serão acima de 150.000 habitantes.

4 IBGE. Perfil dos Municípios Brasileiros 2013 - Pesquisa de Informações Básicas Municipais. Ministério do Planejamento, Orçamento e Gestão. Instituto Brasileiro de Geografia e Estatística. Rio de Janeiro. 2014.

5 https://cidades.ibge.gov.br/brasil/sc/joinville/panorama 

na Tabela 5 .

Os municípios escolhidos agrupados de acordo com seu porte são apresentados

Tabela 5. Portes dos municípios (elaborado pela autora)

\begin{tabular}{|c|c|c|c|}
\hline Porte do município & Município & População $^{6}$ & Mesorregião $^{7}$ \\
\hline \multirow{4}{*}{$\begin{array}{c}\text { Pequeno } \\
\text { (até 50.000 habitantes) }\end{array}$} & Abdon Batista & 2.604 & Serrana \\
\hline & Paulo Lopes & 7.360 & Grande Florianópolis \\
\hline & Urubici & 11.191 & Serrana \\
\hline & Itapiranga & 16683 & Oeste Catarinense \\
\hline \multirow{4}{*}{$\begin{array}{c}\text { Médio } \\
\text { (50.001 a } 150.000 \\
\text { habitantes) }\end{array}$} & Videira & 52.066 & Oeste Catarinense \\
\hline & Rio do Sul & 69.188 & Vale do Itajaí \\
\hline & São Bento do Sul & 82842 & Norte Catarinense \\
\hline & Tubarão & 104457 & Sul Catarinense \\
\hline \multirow{4}{*}{$\begin{array}{c}\text { Grande } \\
\text { (acima de } 150.000 \\
\text { habitantes) }\end{array}$} & Chapecó & 213.279 & Oeste Catarinense \\
\hline & Blumenau & 348.513 & Vale do Itajaí \\
\hline & Florianópolis & 485.838 & Grande Florianópolis \\
\hline & Joinville & 577.077 & Norte Catarinense \\
\hline
\end{tabular}

Os critérios utilizados para a escolha dos municípios foram a variação da população dentro do limite de cada porte e sua localização em diferentes mesorregiões do estado.

A ferramenta foi aplicada no dia 29 de maio de 2018, sobre os sites oficiais dos respectivos municípios. Foi realizada uma observação simples: para cada item presente na ferramenta (diário oficial, leis municipais etc) foi realizada uma busca manual exclusivamente no site oficial, seguindo as questões do checklist. O intuito de manter a avaliação simples, além de facilitar para o avaliador, é possibilitar que todo cidadão com acesso à internet consiga analisar a transparência e criar sistemas que utilizem os dados de seu município, de forma independente. $\mathrm{O}$ resumo dos resultados por item avaliado com suas respectivas médias é apresentado na Tabela 6.

Tabela 6. Resultado dos municípios de pequeno porte (elaborado pela autora)

\begin{tabular}{|c|l|c|c|c|c|}
\hline \multicolumn{5}{|c|}{ Notas do Municípios de Pequeno Porte } \\
\hline $\mathbf{N}^{\mathbf{0}}$ & Itens avaliados & Abdon Batista & Paulo Lopes & Urubici & Itapiranga \\
\hline 1 & Diário Oficial & $\mathbf{6 , 0}$ & $\mathbf{6 , 0}$ & $\mathbf{6 , 0}$ & $\mathbf{6 , 0}$ \\
\hline 2 & Leis Municipais & $\mathbf{6 , 0}$ & $\mathbf{6 , 0}$ & $\mathbf{4 , 8}$ & $\mathbf{6 , 0}$ \\
\hline 3 & $\begin{array}{l}\text { Educação: Quantidade de alunos } \\
\text { por escola }\end{array}$ & $\mathbf{0 , 0}$ & $\mathbf{0 , 0}$ & $\mathbf{0 , 0}$ & $\mathbf{0 , 0}$ \\
\hline 4 & $\begin{array}{l}\text { Transporte Público: Horários por } \\
\text { linha }\end{array}$ & $\mathbf{0 , 0}$ & $\mathbf{0 , 0}$ & $\mathbf{0 , 0}$ & $\mathbf{0 , 0}$ \\
\hline 5 & Remuneração dos servidores & $\mathbf{5 , 0}$ & $\mathbf{8 , 0}$ & $\mathbf{5 , 0}$ & $\mathbf{8 , 0}$ \\
\hline 6 & Despesa Geral & $\mathbf{5 , 0}$ & $\mathbf{8 , 0}$ & $\mathbf{5 , 0}$ & $\mathbf{8 , 0}$ \\
\hline 7 & Receita Geral & $\mathbf{5 , 0}$ & $\mathbf{8 , 0}$ & $\mathbf{5 , 0}$ & $\mathbf{8 , 0}$ \\
\hline 8 & Balanço Orçamentário & $\mathbf{6 , 8}$ & $\mathbf{6 , 0}$ & $\mathbf{4 , 8}$ & $\mathbf{3 , 8}$ \\
\hline
\end{tabular}

6 https://cidades.ibge.gov.br/brasil/sc/

7 http://indicadores.fecam.org.br/indice/mesorregioes/ano/2018 


\begin{tabular}{|rrrr|c|}
\hline TOTAL DO MUNICÍPIO: & 4,2 & 5,3 & 3,8 & 5,0 \\
\hline MÉDIA: & 4,6 \\
\hline
\end{tabular}

O resultado da aplicação nos municípios de médio porte é mostrado na Tabela 7.

Tabela 7. Resultado dos municípios de médio porte (elaborado pela autora)

\begin{tabular}{|c|c|c|c|c|c|}
\hline \multicolumn{6}{|c|}{ Notas dos Municípios de Médio Porte } \\
\hline $\mathbf{N}^{\mathbf{0}}$ & Itens avaliados & Videira & Rio do Sul & São Bento do Sul & Tubarão \\
\hline 1 & Diário Oficial & 6,0 & 6,0 & 6,0 & $6, \mathbf{6}$ \\
\hline 2 & Leis Municipais & $\mathbf{0 , 1}$ & $\mathbf{6 , 0}$ & $6, \mathbf{6 , 0}$ & $\mathbf{6 , 0}$ \\
\hline 3 & $\begin{array}{l}\text { Educação: Quantidade } \\
\text { alunos por escola }\end{array}$ & 3,8 & $\mathbf{0 , 0}$ & 3,8 & $\mathbf{0 , 0}$ \\
\hline 4 & $\begin{array}{l}\text { Transporte Público: Horários } \\
\text { por linha }\end{array}$ & 5,0 & 5,0 & 5,0 & 4,8 \\
\hline 5 & Remuneração dos servidores & 8,0 & 9,0 & 9,0 & 8,0 \\
\hline 6 & Despesa Geral & $8, \mathbf{8}$ & 9,0 & 9,0 & 8,0 \\
\hline 7 & Receita Geral & 8,0 & 9,0 & 9,0 & 8,0 \\
\hline 8 & Balanço Orçamentário & $\mathbf{5 , 0}$ & $\mathbf{9 , 0}$ & 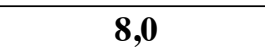 & $8, \mathbf{8 , 0}$ \\
\hline & TOTAL DO MUNICÍPIO: & 5,5 & 6,6 & 7,0 & 6,1 \\
\hline & MÉDIA: & & & & \\
\hline
\end{tabular}

O resultado da aplicação nos municípios de grande porte é mostrado na Tabela 8:

Tabela 8. Resultado dos municípios de grande porte (elaborado pela autora)

\begin{tabular}{|c|c|c|c|c|c|}
\hline \multicolumn{6}{|c|}{ Notas dos Municípios de Grande Porte } \\
\hline $\mathbf{N}^{\mathbf{0}}$ & Itens avaliados & Chapecó & Blumenau & Florianópolis & Joinville \\
\hline 1 & Diário Oficial & 6,0 & 6,0 & 6,0 & $6, \mathbf{6 , 0}$ \\
\hline 2 & Leis Municipais & 6,0 & 6,0 & 6,0 & 6,0 \\
\hline 3 & $\begin{array}{l}\text { Educação: Quantidade de } \\
\text { alunos por escola }\end{array}$ & $\mathbf{0 , 0}$ & $\mathbf{0 , 0}$ & 4,8 & $\mathbf{0 , 0}$ \\
\hline 4 & $\begin{array}{l}\text { Transporte Público: Horários } \\
\text { por linha }\end{array}$ & $\mathbf{0 , 0}$ & 5,0 & 6,0 & 6,0 \\
\hline 5 & Remuneração dos servidores & 8,0 & 5,0 & 5,0 & $6, \mathbf{6 , 0}$ \\
\hline 6 & Despesa Geral & 8,0 & 7,8 & 8,0 & 9,0 \\
\hline 7 & Receita Geral & 8,0 & 7,8 & 8,0 & 9,0 \\
\hline 8 & Balanço Orçamentário & 6,0 & 3,8 & 4,8 & $\mathbf{6 , 0}$ \\
\hline & TOTAL DO MUNICÍPIO: & 5,3 & 5,2 & 6,1 & 6,0 \\
\hline & MÉDIA: & & 5, & & \\
\hline
\end{tabular}

A média das notas dos municípios de pequeno, médio e grande porte foram 4,6;6,3 e 5,6 , respectivamente. Isto resultou em uma média geral de 5,5 pontos. ${ }^{8}$

\section{Relação entre transparência e porte do município}

Esta seção verifica se há uma relação entre a qualidade da transparência de dados do município e o seu tamanho. 
Referente aos municípios classificados como pequeno porte, nenhum apresentou dados sobre a quantidade de alunos matriculados por escola fundamental, tampouco sobre os horários das linhas do transporte público. O gráfico que representa o resultado por critério analisado é apresentado na Figura 2.

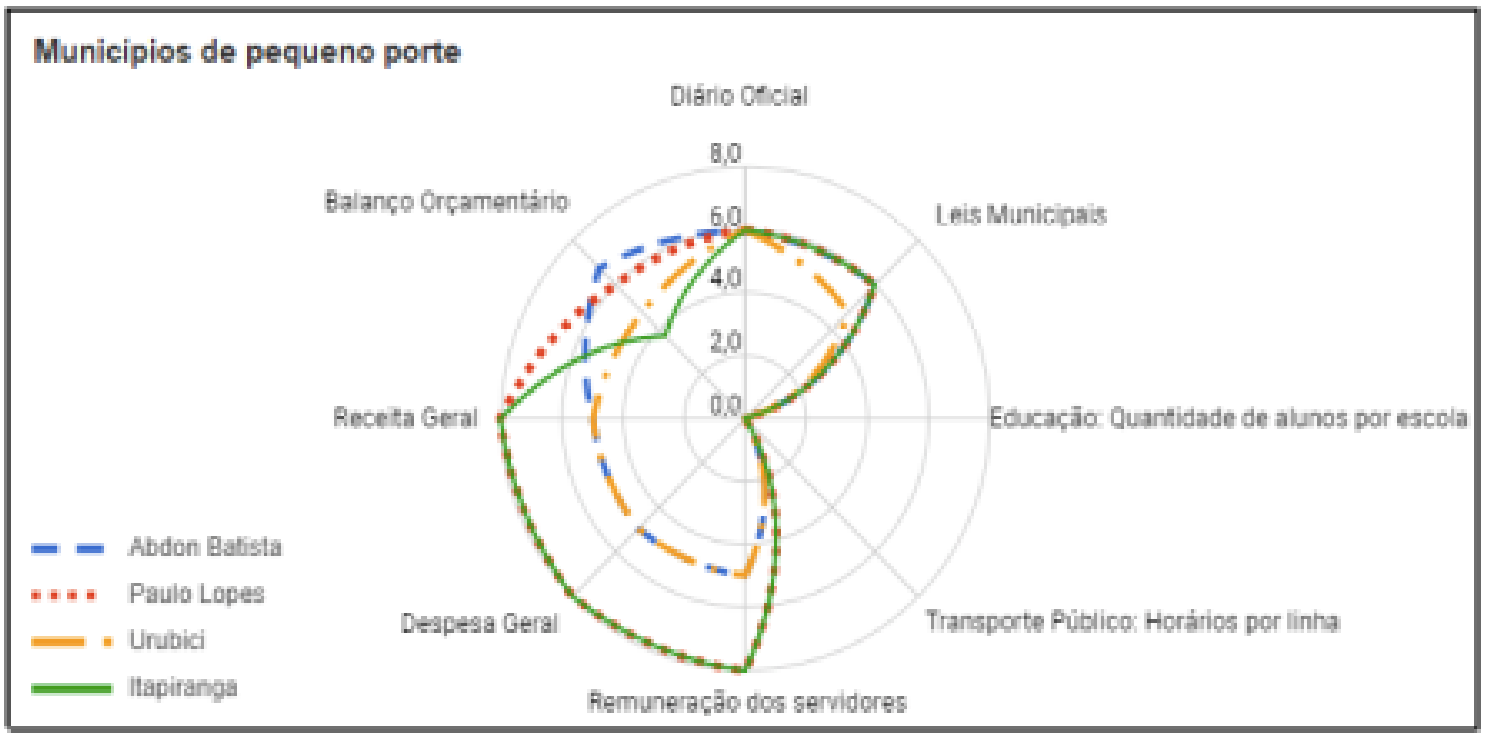

Figura 2. Gráfico com resultados: Pequeno porte (elaborado pela autora)

De forma geral, os municípios de pequeno porte obtiveram desempenho semelhante entre eles sobre os critérios analisados, onde a maior variação de pontuação se deu a respeito do balanço orçamentário. Os municípios de Paulo Lopes e Itapiranga atingiram a mesma nota sobre a remuneração dos servidores, a despesa geral e a receita geral, enquanto Abdon Batista e Urubici alcançaram notas iguais, sobre estes mesmos critérios.

Sobre os municípios de médio porte analisados, apenas Videira e São Bento do Sul disponibilizaram dados sobre a quantidade de alunos por escola fundamental. Todos os municípios de médio porte analisados apresentaram informação sobre horários por linha do transporte público, diferentemente dos municípios de pequeno porte, onde nenhum informou esses dados. Em relação às leis municipais, apenas o município de Videira disponibilizou um link para acesso, mas sem dados nele. De modo geral, nos demais critérios avaliados, os municípios alcançaram pontuações semelhantes. O gráfico com as pontuações dos critérios é apresentado na Figura 3 a seguir.

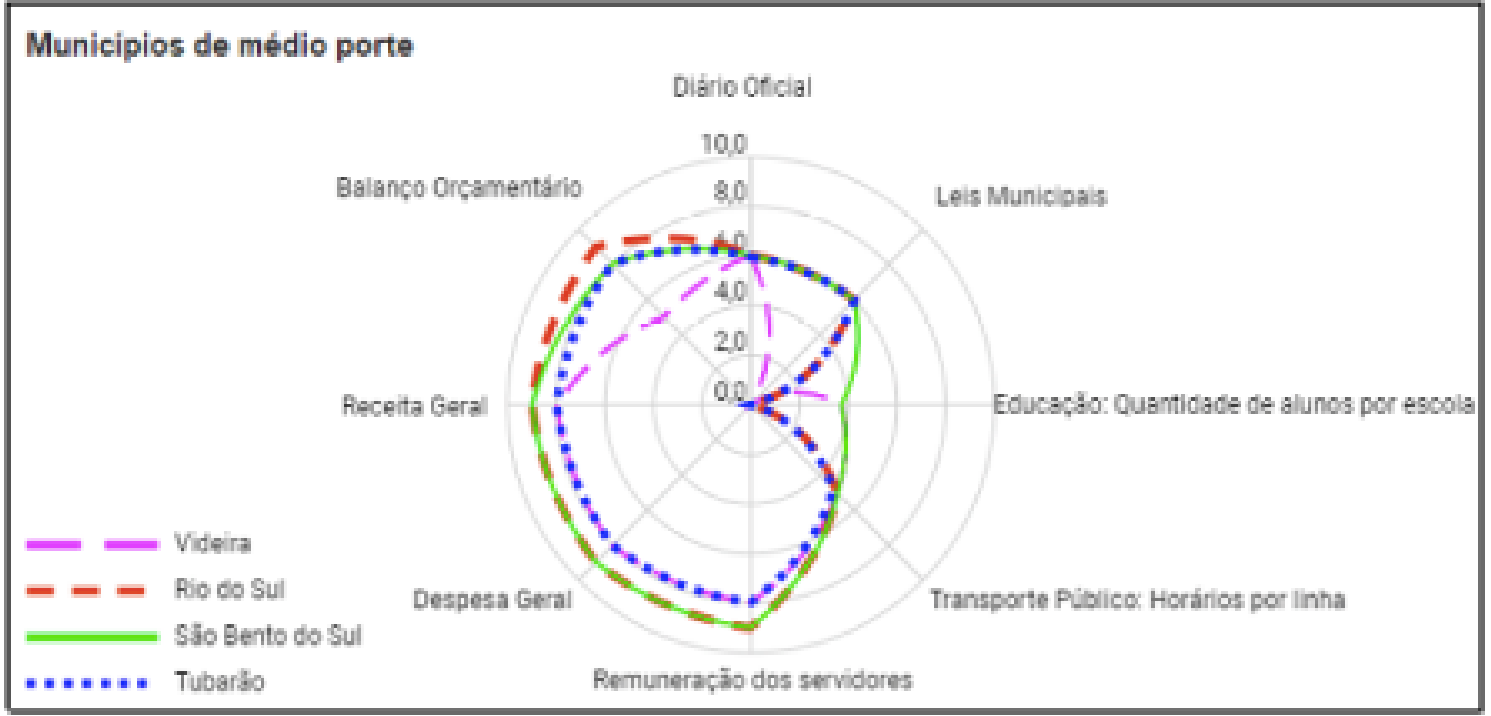


Figura 3. Gráfico com resultados: Médio porte (elaborado pela autora)

Os municípios de grande porte pesquisados apresentaram, na maior parte dos casos, desempenhos similares sobre os critérios avaliados. O gráfico apresentado na Figura 4 mostra o resultado dos municípios por critério.

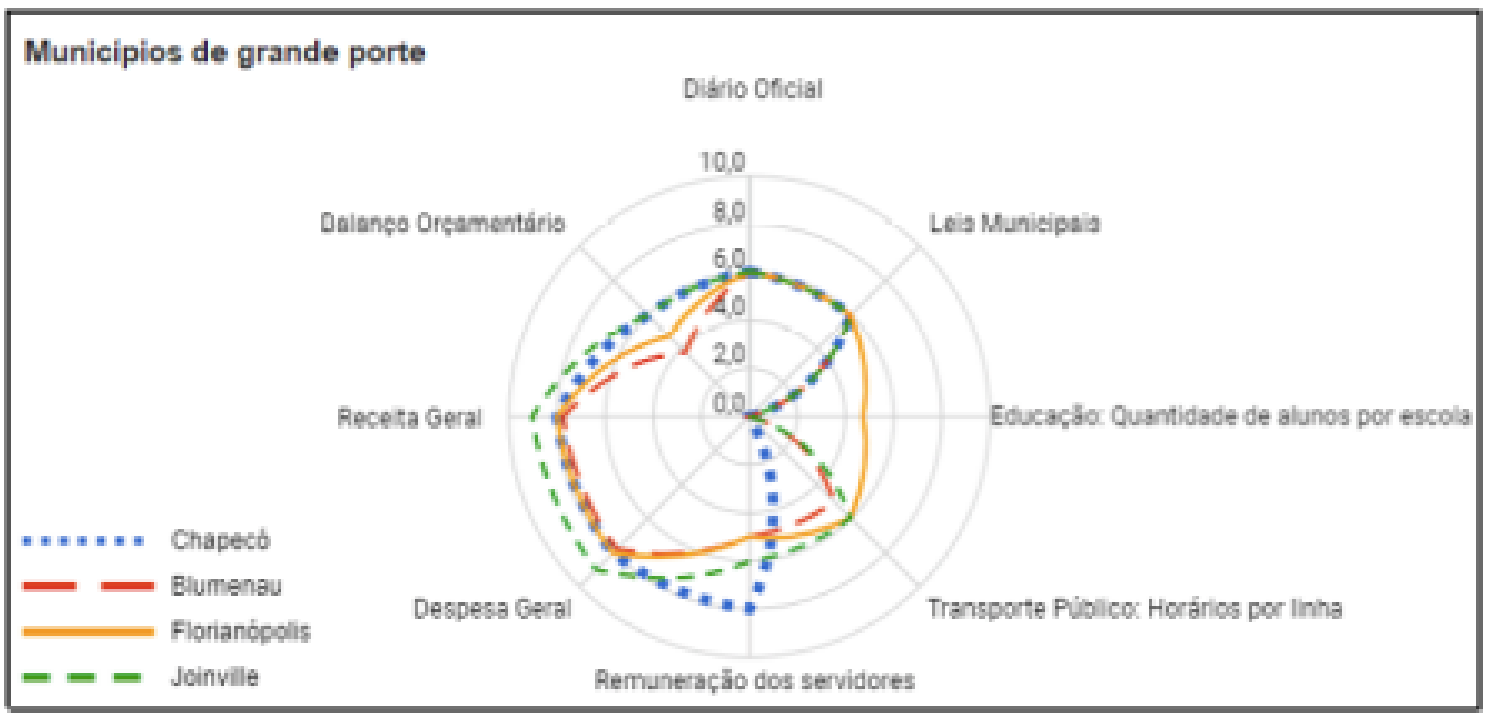

Figura 4. Gráfico com resultados: Grande porte (elaborado pela autora)

A respeito do item sobre a quantidade de alunos por escola fundamental, apenas o município de Florianópolis apresentou algum dado. Assim como todos os municípios de pequeno e médio porte analisados, os municípios de grande porte apresentaram a mesma pontuação sobre o item diário oficial.

A Figura 5 apresenta um gráfico com uma visão geral do resultado de todos os municípios avaliados com a ferramenta Escala Santa Catarina Transparente.

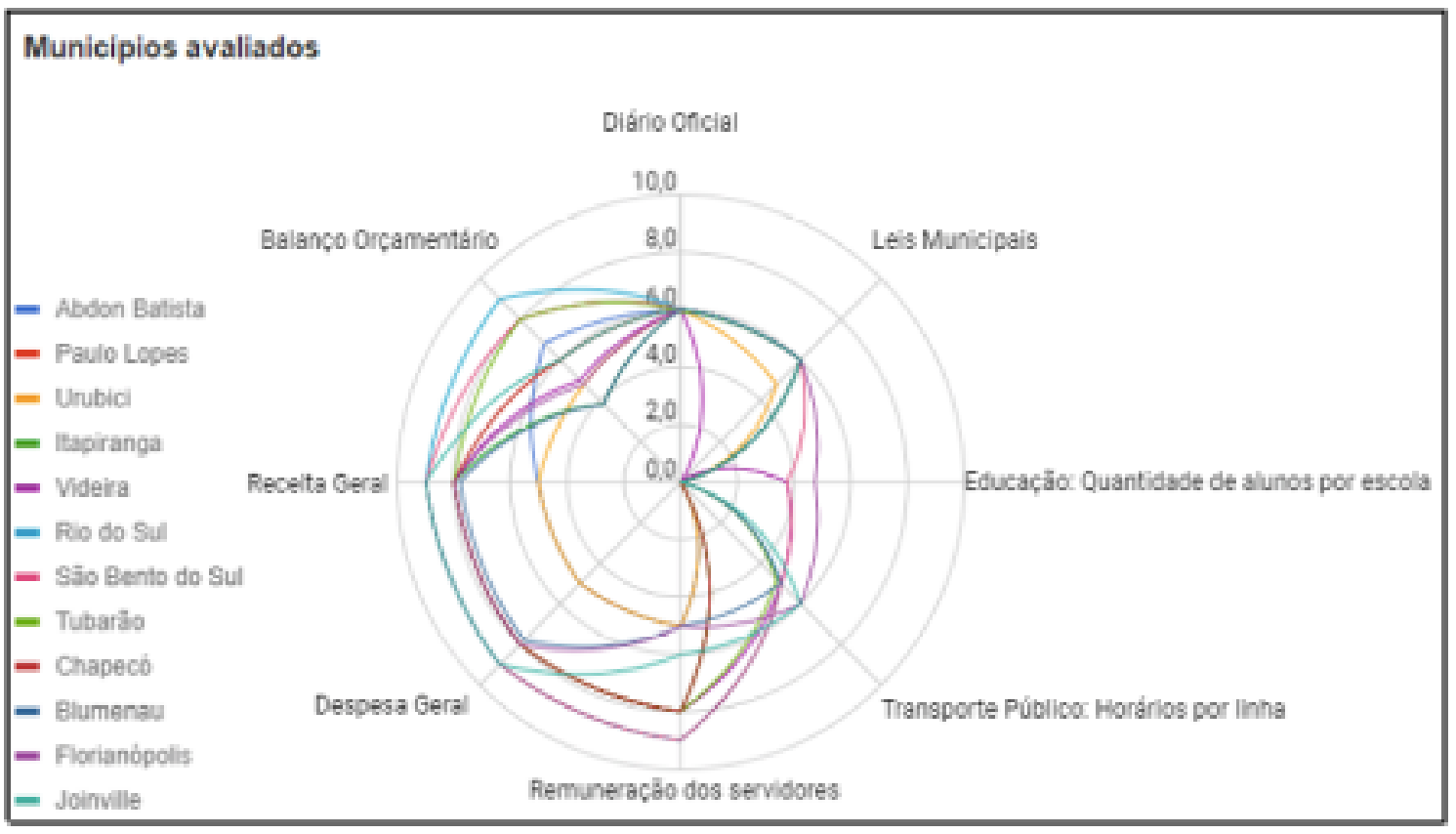

Figura 5. Gráfico com visão geral dos resultados (elaborado pela autora)

Observa-se que os critérios com maior variação de pontuação entre os municípios são balanço orçamentário, leis municipais, quantidade de alunos por escola fundamental, horários por linha do transporte público e remuneração dos servidores. Ainda, há um 
padrão entre a maioria dos municípios em oferecer uma qualidade de transparência maior em relação aos dados financeiros, independente de seu porte. Além disso, o item com menor disponibilização de dados é a quantidade de alunos por escola, seguido dos horários por linha do transporte público. Uma possível causa que leve os municípios a não disponibilizarem esses dados é a falta da exigência explícita para disponibilização deles em lei.

Assim, fica a critério do órgão municipal responsável pela transparência pública julgar quais informações que não têm obrigatoriedade explícita em lei serão disponibilizadas, salvo os casos em que o município regulamenta a lei e determina explicitamente todos os dados que devem ser fornecidos.

Durante a aplicação da ferramenta Escala Santa Catarina Transparente nos municípios, percebeu-se que muitos deles utilizam o mesmo sistema ou serviço de terceiros para disponibilizar seus dados. Para dispor os dados referentes às despesas, receitas, balanço orçamentário e remuneração dos servidores públicos, alguns municípios utilizam o sistema "Transparência Fly" ou o serviço "Atende.net ${ }^{10 "}$ ". Para divulgação das leis municipais, grande parte dos municípios verificados utilizam o serviço "Leis municipais ${ }^{11}$ ". Em relação ao diário oficial, todos os municípios analisados utilizam o "Diário Oficial dos Municípios - DOM" ${ }^{12}$ ", um site de divulgação de atos oficiais administrativos oferecido pela Federação Catarinense de Municípios (FECAM). A utilização unânime do "Diário Oficial dos Municípios - DOM" pelos municípios resultou em uma nota igual no critério diário oficial para todos, conforme pode ser verificado no gráfico anterior.

O uso de um único sistema por diversos municípios resulta numa performance sobre qualidade de transparência de dados similares entre os municípios que os usam, onde a diferença cabe aos aspectos que dependem do órgão ou entidade que dispõe a informação, como existência e atualidade do dado e, em alguns casos, seu formato. Ademais, informações sobre diversos municípios concentrados em um único sistema, como o caso do DOM, facilitam sua busca por quem deseja um mesmo dado sobre diferentes municípios, além de aumentar a qualidade da transparência em vários municípios de uma única vez ao realizar possíveis melhorias no sistema, como o formato disponibilização dos dados, por exemplo.

Considerando as informações apresentadas e que exclusivamente no grupo dos municípios de pequeno porte, nenhum disponibilizou dados sobre a quantidade de alunos por escola nem os horários por linha do transporte público, além de obter a menor média, sendo 4,6 contra 6,3 para porte médio e 5,6 para porte grande. É possível levantar a hipótese de que os municípios de pequeno porte tendem a obter notas menores se comparado com os de médio e grande porte por não disponibilizarem dados que não estão previstos na lei, mas que são de interesse à população. Portanto, há possibilidade da existência de uma relação entre o tamanho do município e a qualidade de transparência de seus dados. Ainda, a pequena diferença das médias das notas dos municípios de médio e grande porte (diferença de 0,7 ponto) em conjunto com um desempenho similar entre eles pode indicar que não há uma diferença significativa de qualidade da transparência de dados entre estes portes específicos. Entretanto, é necessário uma análise mais profunda sobre uma quantidade maior de municípios para que o resultado seja significativo e possível de afirmar ou negar tais hipóteses levantadas.

9 https://e-gov.betha.com.br/transparencia/01034-007/main.faces

10 Site de exemplo: https://www.ipm.com.br/portal-transparencia/

11 https://leismunicipais.com.br/

12 https://www.diariomunicipal.sc.gov.br/site/

isys: Revista Brasileira de Sistemas de Informação (isys: Brazilian Journal of Information Systems) http://seer.unirio.br/index.php/isys/ 


\section{Considerações finais}

$\mathrm{O}$ acesso à informação têm crescentemente se mostrado relevante na sociedade globalizada atual. Sua importância foi destacada ao longo do presente trabalho, de maneira que seu desenvolvimento foi justificado pela necessidade de se obter dados utilizáveis e com qualidade.

A pesquisa da fundamentação teórica revelou que nos últimos anos têm crescido a quantidade de leis e ações que garantem a distribuição de informação, bem como o surgimento de entidades e organizações governamentais e não-governamentais que fiscalizam, promovem e incentivam a abertura de dados governamentais, a nível local e global. O intuito da disponibilização dos dados governamentais, além de prestar contas e manter os cidadãos informados, é permitir que a própria população desenvolva inovações que se alimentam desses dados para causar um impacto positivo na sociedade. Contudo, a principal dificuldade é localizar dados com qualidade e características que permitam serem utilizados por esses sistemas. Verificou-se que aspectos técnicos vinculados às informações, como ter licença aberta, ser nãoproprietário e legível por máquina são imprescindíveis para tornar viável o desenvolvimento de sistemas e aplicações.

A análise comparativa entre os métodos de avaliação de transparência de dados Escala Brasil Transparente, Open Data Barometer e Open Data Index indicando os principais pontos fortes e fracos de cada método cumpriu o primeiro objetivo do presente trabalho. Verificou-se que o método Escala Brasil Transparente é utilizado pelos órgãos fiscalizadores da transparência de dados no Brasil e é, portanto, específico para o Brasil, avaliando o cumprimento da lei. Além disso, é simples de aplicar pois não depende de especialistas e é composto por respostas binárias que evitam a subjetividade do avaliador. Por outro lado, este método não avalia transparência ativa, tampouco o formato em que os dados são disponibilizados. Em relação ao método Open Data Barometer, indicou-se como principais pontos fortes $\mathrm{o}$ fato de ser padronizado internacionalmente, permitindo comparação com outros países, a validação dos formatos dos dados disponibilizados e a realização de uma análise sobre o impacto político, social e econômico da transparência dos dados governamentais. Contudo, ele não avalia transparência passiva e depende de pesquisadores e especialistas, tornando sua implementação complexa. Ainda, o resultado obtido através deste método depende do julgamento dos pesquisadores, além de não abranger características específicas das leis locais. A respeito do método Open Data Index, as características indicadas como positivas são a padronização internacional e a validação sobre o formato em que os dados são disponibilizados. Entretanto, assim como no método Open Data Barometer, foi verificado que este método não avalia a transparência passiva, é complexo por depender de voluntários e de especialistas, não abrange características específicas das leis locais e seu resultado depende do julgamento dos voluntários.

Os principais aspectos levados em consideração na análise foram a verificação quanto ao formato de disponibilização dos dados, relevante para sua efetiva utilização em sistemas informacionais; a complexidade de implementação, importante para municípios de pequeno porte; a verificação do cumprimento de leis específicas de cada local e se o resultado é de alguma forma influenciado pela subjetividade dos pesquisadores.

Em suma, conclui-se que ferramentas internacionais são mais complexas na implementação pois possuem mais etapas de avaliação e dependem de especialistas, pesquisadores ou voluntários para sua execução. Além disso, são focadas na transparência ativa e não abrangem aspectos das leis específicas de cada país. Entretanto, elas permitem a comparação dos resultados de diversos países, construindo um panorama global a respeito da transparência de dados. A ferramenta brasileira Escala Brasil Transparente é mais simples de implementar pois depende de poucos avaliadores e é feita em uma etapa - a aplicação do checklist. Dentre as ferramentas 
analisadas, esta é a única que avalia a transparência passiva do governo e o cumprimento da lei nos municípios. Com isso, ela permite a comparação dos resultados de diversos municípios brasileiros, construindo um panorama nacional a respeito da transparência de dados.

A ferramenta de avaliação da qualidade da transparência dos dados públicos dos municípios catarinenses Escala Santa Catarina Transparente proposta no presente trabalho alcançou o segundo objetivo do mesmo. O intuito desta ferramenta é avaliar a transparência ativa dos municípios e a forma como os dados são disponibilizados, tendo como objeto de avaliação seus respectivos sites oficiais. A ferramenta é composta por uma planilha eletrônica no formato ".ods" (OpenDocument), sendo legível por máquina e livre de softwares licenciados, com uma lista de questões com resposta binária para evitar ao máximo a subjetividade do avaliador. As questões tratam a disponibilidade online do dado, se ele está atualizado e de que forma ele está disponível. Outro ponto levando em consideração foi manter a métrica simples, de maneira que os pequenos municípios possam utilizá-la para autoavaliação sem a necessidade de especialistas.

Através da aplicação da ferramenta Escala Santa Catarina Transparente, constatou-se que, exclusivamente no grupo dos municípios de pequeno porte, nenhum município disponibilizou dados sobre quantidade de alunos por escola tampouco sobre horários por linha do transporte público. Ademais, o grupo dos municípios de pequeno porte obtiveram a menor média, sendo 4,6 contra 6,3 para médio porte e 5,6 para grande porte. Então, foi percebido que é possível levantar a hipótese de que os municípios de pequeno porte tendem a obter notas menores se comparado com os de médio e grande porte devido à não disponibilizarem dados que não estão previstos na lei, mas que são de interesse à população, além de obterem notas menores sobre os dados já disponibilizados. Portanto, concluiu-se que há possibilidade da existência de uma relação entre o tamanho do município e a qualidade de transparência de seus dados.

\section{Referências}

ALENCAR, Anderson Fernandes de et al (2009). "Software livre, cultura hacker e o ecossistema da colaboração". São Paulo: Momento Editorial. 272 p.

AMARAL, Sueli Angelica do; AROUCK, Osmar (2013). "Atributos da qualidade da informação e a lei de acesso à informação". Anais do XXV Congresso Brasileiro de Biblioteconomia, Documentação e Ciência da Informação. Florianópolis.

ARAÚJO, Narallynne Maciel de (2017). "Dados abertos do governo brasileiro: entendendo as perspectivas de fornecedores de dados e desenvolvedores de aplicações ao cidadão". 136 f. Dissertação (Mestrado em Sistemas e Computação) Programa de Pós-Graduação em Sistemas e Computação, Universidade Federal do Rio Grande do Norte, Rio Grande do Norte.

BRASIL. CONTROLADORIA GERAL DA UNIÃO (2014). "Parceria para Governo Aberto: O que é a iniciativa". Dezembro. http://www.governoaberto.cgu.gov.br/aogp/o-que-e-a-iniciativa\#acontent.

BRASIL. MINISTÉRIO DA TRANSPARÊNCIA E CONTROLADORIA-GERAL DA UNIÃO (2017). "Metodologia", http://www.cgu.gov.br/assuntos/transparenciapublica/escala-brasil-transparente/metodologia.

BRASIL. MINISTÉRIO DA TRANSPARÊNCIA, FISCALIZAÇÃO E CONTROLADORIA-GERAL DA UNIÃO (2016). "Aplicação da lei de acesso à informação na Administração Pública Federal". 2. ed. Brasília: Imprensa Nacional, 98 p. http://www.acessoainformacao.gov.br/central-de-conteudo/publicacoes/ arquivos/aplicacao lai 2edicao.pdf. 
BRASIL. Rogério Jordão. Controladoria Geral da União (Org.) (2011). "Acesso à Informação Pública: Uma introdução à Lei 12.527, de 18 de novembro de 2011". Brasília: Imprensa Nacional. 25 p.

CANHADAS, Fernando Augusto Martins (2012). "O princípio da transparência na administração pública: a transparência obrigatória, a transparência permitida e a transparência proibida”. 417 p. Tese (Doutorado em Direito) - Pontifícia Universidade Católica de São Paulo, São Paulo.

CASTELLS, Manuel (2009). “Comunicación y poder”. Madrid: Alianza Editorial, 679 p.

DA SILVA, Clayton Ferreira et al (2014). "Dados abertos: uma estratégia para o aumento da transparência e modernização da gestão pública". Revista do TCU, n. 131, p. $22-29$.

DAVIES, T (2013). “Open Data Barometer 2013 Global Report”. World Wide Web Foundation and Open Data Institute. 45 p. http://opendatabarometer.org/doc/1stEdition/Open-Data-Barometer-2013-GlobalReport.pdf.

DE FERRANTI, D.M.; JACINTO, J.; ODY, A. J.; RAMSHAW, G (2009)., "How to Improve Governance: a New Framework for Analysis and Action". Washington: Brookings Institution Press. 189 p.

EAVES, David (2009). "The Three Laws of Open Government Data". https://eaves.ca/2009/09/30/three-law-of-open-government-data/.

HARRISON, T. M. et al (2011). "Open government and e-government: Democratic challenges from a public value perspective". Center for Technology in Government U/Albany. $\quad$ Information $\quad$ Polity. 9 https://www.ctg.albany.edu/media/pubs/pdfs/dgo2011 opengov.pdf.

HAUSENBLAS, Michael (2012). "5 estrelas dos dados abertos", http://5stardata.info/pt-BR/.

LINHARES, Fernando Moura (2011). "O direito de acesso às informações públicas nas democracias representativas contemporâneas". 162 p. Dissertação (Mestrado em Direito) - Centro de Ciências Jurídicas, Universidade de Fortaleza, Fortaleza.

MENDEL, Toby (2009). "Liberdade de informação: um estudo de direito comparado". 2. ed. Brasília: Unesco. 161 p.

OLIVEIRA, João Nuno; AMARAL, Luís Alfredo (1999). "O papel da qualidade da informação nos sistemas de informação". Conferência Especializada em Sistemas E Tecnologias de Informação. p.17.

ONU (1948). "Declaração Universal dos Direitos Humanos". Artigo 19, https://nacoesunidas.org/wp-content/uploads/2018/10/DUDH.pdf.

OPEN DATA BAROMETER (2016). “ODB Methodology”. 16 p. http://opendatabarometer.org/doc/4thEdition/ODB-4thEdition-Methodology.pdf.

OPEN DATA CENSUS. BRAZIL OPEN DATA CENSUS (2017a). "Methodology", http://br-city.survey.okfn.org/methodology/.

OPEN DATA CENSUS. BRAZIL OPEN DATA CENSUS (2017b). "Open Data Index - Measuring open data around the world", http://br-cities.survey.okfn.org/about/.

OPEN DATA CENSUS. BRAZIL OPEN DATA CENSUS (2017c). “Tutorial - Open Data Index 2017”, http://br-city.survey.okfn.org/tutorial/.

OPEN GOVERNMENT DATA (2007). "Eight principles of open government data", https://public.resource.org/8 principles.html. 
OPEN KNOWLEDGE BRASIL (2013). "Maturidade em Dados Abertos: Entenda as 5 Estrelas". Elaborado por Nitai Silva, https://br.okfn.org/2013/01/17/maturidade-emdados-abertos-entenda-as-5-estrelas/.

OPEN KNOWLEDGE FOUNDATION (2017). “Guide. O que são Dados Abertos?”, http://opendatahandbook.org/guide/pt BR/what-is-open-data/

SILVEIRA, Sérgio Amadeu da (2010). "Ciberativismo, cultura hacker e o individualismo colaborativo”. Revista USP, São Paulo, n. 86, p.28-39, jun/ago.

STRONG, Diane M. Strong; LEE, Yang W.; WANG, Richard Y (1997). "Data Quality In Context: A new study reveals businesses are defining data quality with the consumer in mind". Communications of the ACM. Vol. 40, n. 5, p. 103-110.

THE OPEN DATA BAROMETER (2017). "About", http://opendatabarometer.org/barometer/.

UBALDI, Barbara (2013). "Open Government Data: Towards Empirical Analysis of Open Government Data Initiatives". OECD Working Papers on Public Governance, No. 22. Paris: OECD Publishing.

UGARTE, David de (2008). “O poder das redes”. Porto Alegre: EDIPUCRS. 116 p.

VAZ, J.; RIBEIRO, M.; MATHEUS, R (2011). "Open government data and its impact on the concepts and practices of transparency in brazil”. Cadernos PPGAU/UFBA, p. 4562.

VEGH, Sandor (2003). "Classifying forms of online activism: the case of cyberprotests against the World Bank". Em: MCCAUGHEY, Martha; AYERS, Michael D. "Cyberactivism: online activism in theory and practice". New York: Routledge-usa, p. 71-95.

WEINSTEIN, Jeremy; GOLDSTEIN, Joshua (2012). "The Benefits of a Big Tent: Opening Up Government in Developing Countries - A Response to Yu \& Robinson's The New Ambiguity of "Open Government". UCLA Law Review Disclosure. V. 60 , n. 38, p. 40-48, http://www.uclalawreview.org/pdf/discourse/60-3.pdf. 